Supporting Information

\title{
A Tumor Microenvironment-Responsive and Catalytic Cascade-Enhanced Nanocomposite for Tumor Thermal Ablation Synergizing with Chemodynamic and Chemotherapy
}

Ye Zhang ${ }^{a}, Y_{i} \mathrm{Cao}^{a}$, *, Tian $\mathrm{Gao}^{a}$, Ye Kuang ${ }^{b}$, Zhen $\mathrm{An}^{a}$, Zheng Mao ${ }^{a}$, Yilin $\mathrm{He}^{a}$, Jincong Yan ${ }^{a}$, Zhongzhong Lü, Renjun Pei ${ }^{a, *}$

${ }^{a}$ CAS Key Laboratory for Nano-Bio Interface, Suzhou Institute of Nano-Tech and Nano-Bionics, Chinese Academy of Sciences, Suzhou, 215123, China

${ }^{\mathrm{b}}$ Higher Educational Key Laboratory for Nano Biomedical Technology of Fujian Province, Fujian Medical University, Fuzhou, 350004, China

*Corresponding author.

E-mail address: ycao2014@sinano.ac.cn (Dr. Y. Cao) rjpei2011@sinano.ac.cn (Prof. R. Pei) 


\section{Experimental Section}

Materials. 3-Hydroxytyramine hydrochloride, Poly (allylamine hydrochloride) (PAH, 18-20 kDa), methylene blue (MB) and terephthalic acid (TA) were purchased from Admas Reagent Co. Ltd. Potassium permanganate $\left(\mathrm{KMnO}_{4}\right)$, glucose and dimethylsulfoxide (DMSO) were acquired from Shanghai Chemical Co. (China). Sodium hyaluronate (HA, $40 \mathrm{kDa}$ ) was acquired from Freda Biochem Co. Ltd. (Shandong, China). Hydrogen peroxide aqueous solution $\left(\mathrm{H}_{2} \mathrm{O}_{2}, 3 \%\right)$, glutathione (GSH), Poly (acrylic acid sodium salt) (PAA, 5 kDa), Glucose Oxidase (GOD), 5,5’Dithiobis (2-nitrobenzoic acid) (DTNB) and Thiazolyl blue tetrazolium bromide (MTT) were acquired from Sigma-Aldrich Corp. Doxorubicin hydrochloride $(\mathrm{DOX} \cdot \mathrm{HCl})$ was obtained from Energy Chemical (Shanghai, China). Fetal bovine serum (FBS), highglucose and glucose free dulbecco's modified eagle's medium (DMEM), penicillin/streptomycin, and trypsin were purchased from GIBCO Life Technologies. ROS-ID Hypoxia/Oxidative Stress Detection Kit was purchased from Enzo Life Sciences. Annexin V-FITC/PI apoptosis kit was obtained from KeyGen Biotech Co., Ltd. Reactive Oxygen Species Assay Kit (DCFH-DA) and Hoechst 33342 were provided by Beyotime Institute of Biotechnology. Lysotracker Green DND-26 was from life technologies (Thermo Fisher Scientific).

Synthesis of PDA nanoparticles. PDA nanoparticles were prepared according to the previous literature ${ }^{[1]}$. Typically, $3 \mathrm{~mL}$ of ammonia aqueous solution was mixed with $40 \mathrm{~mL}$ of ethanol and $90 \mathrm{~mL}$ of deionized water for $30 \mathrm{~min}$ under stirring at $30^{\circ} \mathrm{C}$. Then, $0.5 \mathrm{~g}$ of dopamine hydrochloride was dissolved in deionized water $(10 \mathrm{~mL})$ and 
quickly added into the above mixture solution. The reaction was kept for $24 \mathrm{~h}$. The resulting PDA nanoparticles were obtained by centrifugation and washed with water to remove residual dopamine.

Synthesis of PDA@MnO nanoparticles.15 mg of PDA nanoparticles were dispersed in $10 \mathrm{~mL}$ of deionized water and added into $20 \mathrm{~mL}$ of $\mathrm{KMnO}_{4}$ solution $(75$ mg/mL). After stirring for $1 \mathrm{~h}$, the as-prepared PDA@ $\mathrm{MnO}_{2}$ nanoparticles were washed and re-dispersed in water.

Synthesis of $\mathrm{HMnO}_{2}$ nanoparticles. PDA@ $\mathrm{MnO}_{2}$ nanoparticles were resuspended in deionized water at a concentration of $200 \mu \mathrm{g} / \mathrm{mL}$, and a certain amount of GSH was added into the PDA@ $\mathrm{MnO}_{2}$ solution to make the final concentration of GSH in this reaction is $1 \mathrm{mM}$. After stirring for $10 \mathrm{~min}$, the resulted $\mathrm{HMnO}_{2}$ nanoparticles were harvested by centrifugation and washed with deionized water.

Synthesis of $\mathrm{HMnO}_{2}-\mathrm{GOD}-\mathrm{HA}$ nanoparticles. First, a certain amount of $\mathrm{HMnO}_{2}$ nanoparticles were added dropwise to $5 \mathrm{mg} / \mathrm{mL}$ of PAH solution and the mixture was stirred for $2 \mathrm{~h}$. After centrifugation and washed, the PAH-modified $\mathrm{HMnO}_{2}-\mathrm{PAH} \mathrm{NPs}$ were re-dispersed in $2 \mathrm{~mL}$ of water and mixed with $10 \mu \mathrm{L}$ of GOD $(10 \mathrm{mg} / \mathrm{mL})$ aqueous solution. At the same time, $40 \mathrm{mg}$ of HA was dissolved by $20 \mathrm{~mL}$ of water and stirred in a glass flask, then, the mixture of nanoparticles and GOD was added into the HA aqueous solution and stirred for another $2 \mathrm{~h}$. The $\mathrm{HMnO}_{2}$-GOD-HA nanoparticles were collected by centrifugation and washed with water three times. To prepare $\mathrm{HMnO}_{2}-\mathrm{HA}$ and $\mathrm{HMnO}_{2}$-GOD-PAA as controls, similar procedures were followed, but without GOD addition or using non-targeting PAA instead of targeting HA. 
Preparation of DOX and GOD-coloaded $\mathrm{HMnO}_{2}-\mathrm{DOX}$-GOD-HA nanoparticles.

A certain amount of DOX was dissolved in DMSO and added into $\mathrm{HMnO}_{2}$ aqueous solution at a mass ratio of 1:1. The mixture was stirred in the dark for $24 \mathrm{~h}$ under room temperature, and then the DOX loaded $\mathrm{HMnO}_{2}$ nanoparticles were collected by centrifugation and washed with water several times until the supernatant became clear. Subsequently, PAH modified DOX loaded $\mathrm{HMnO}_{2}$ and $\mathrm{HA}$ modified DOX and GODcoloaded $\mathrm{HMnO}_{2}$-DOX-GOD-HA nanoparticles were prepared as the abovementioned procedure. To determine the DOX loading content in $\mathrm{HMnO}_{2}$-DOX-GODHA nanoparticles, the centrifuge supernatants in PAH and HA modification process were respectively collected and diluted to the constant volume in the volumetric flasks.

Characterization. The morphology and structure of $\mathrm{PDA}, \mathrm{HMnO}_{2}$ and $\mathrm{HMnO}_{2}-$ DOX-GOD-HA nanoparticles were observed through a transmission electron microscope (HT7700, Hitachi, Japan) with an accelerated voltage of $120 \mathrm{kV}$. The scanning transmission electron microscopy were performed on a Philips Tecnai G2 F20 electron microscope at $200 \mathrm{kV}$ to determine the chemical compositions as well as their distribution in the nanoparticles. The hydrodynamic diameters and zeta potentials of samples were carried out with a Malvern Zetasizer Nano ZS90 analyzer (Worcestershire, UK). The XPS spectra were recorded with a spectrophotometer (ESCALAB250). The concentration of Mn in samples was determined by inductively coupled plasma mass spectroscopy (ICP-MS, Thermo Fisher iCAP Q). The absorption spectra of samples were measured using a UV-vis spectrophotometer (Lambda 25, PerkinElmer, USA). The loading content of DOX in nanoparticles were determined by 
the UV-Vis spectrophotometer through measuring the absorbance value of collected supernatant at $480 \mathrm{~nm}$. According to the standard curve of DOX at $480 \mathrm{~nm}$ and the volume of supernatant, the amount of DOX in each volumetric flask corresponding to each modification can be calculated. The loading content (DL) and encapsulation efficiency (EE) of DOX were calculated by the following formulas:

$$
\begin{aligned}
& D L(\%)=\frac{\text { amount of DOX loaded in nanoparticles }}{\text { total amount of nanoparticles and DOX }} \times 100 \% \\
& E E(\%)=\frac{\text { amount of DOX loaded in nanoparticles }}{\text { total amount of DOX in the system }} \times 100 \%
\end{aligned}
$$

Degradation behavior. In vitro degradation property of $\mathrm{HMnO}_{2}$-DOX-GOD-HA nanoparticles under various conditions was studied by measuring the concentration of accumulated free Mn ions degraded from nanoparticles by ICP-MS. The different PBS solutions containing $200 \mu \mathrm{g} / \mathrm{mL} \mathrm{HMnO}_{2}$-DOX-GOD-HA were shaken gently at $37^{\circ} \mathrm{C}$. And then, at certain time intervals, a small amount of solution was taken out and centrifuged, the Mn concentration in the supernatant was measured by ICP-MS.

Extracellular Depletion of GSH. Total GSH was measured by UV-Vis spectroscopy. A DTNB PBS solution (30 mM, $200 \mu \mathrm{L})$, GSH aqueous solution (10 $\mathrm{mM}, 24 \mu \mathrm{L}$ ) and different concentration of $\mathrm{HMnO}_{2}-\mathrm{HA}$ nanoparticles aqueous solution were mixed to reach the final volume of $1.2 \mathrm{~mL}$ and further maintained at $25{ }^{\circ} \mathrm{C}$ for 30 min, then centrifuged to remove nanoparticles, and the absorbance change of the supernatant at $412 \mathrm{~nm}$ was measured.31

Extracellular $\cdot \mathrm{OH}$ generation. When use TA as the probe, $25 \mathrm{mM} \mathrm{NaHCO} / 5 \%$ $\mathrm{CO}_{2}$ buffer solution containing $6 \mathrm{mM} \mathrm{TA}, 8 \mathrm{mM} \mathrm{H}_{2} \mathrm{O}_{2}$, various $\mathrm{GSH}, \mathrm{Mn}^{2+}$ or $\mathrm{HMnO}_{2^{-}}$ HA nanoparticles at Mn concentration of $5 \mathrm{mM}$ were allowed to stand at $37{ }^{\circ} \mathrm{C}$ for $8 \mathrm{~h}$. 
After that, the mixture centrifuged and took the supernatant for measuring the fluorescence spectra with $\lambda_{\mathrm{ex}}=315 \mathrm{~nm}$. When use MB as the probe, $10 \mu \mathrm{g} / \mathrm{mL} \mathrm{MB}, 8$ $\mathrm{mM} \mathrm{H}_{2} \mathrm{O}_{2}$, various $\mathrm{GSH}, \mathrm{Mn}^{2+}$ or $\mathrm{HMnO}_{2}$-HA nanoparticles at $\mathrm{Mn}$ concentration of 5 $\mathrm{mM}$ in $25 \mathrm{mM} \mathrm{NaHCO} 3 / 5 \% \mathrm{CO}_{2}$ buffer were kept at $37{ }^{\circ} \mathrm{C}$ for $30 \mathrm{~min}$. Then, the mixture was centrifugated, and the absorbance of the supernatant at $655 \mathrm{~nm}$ was measured.

Extracellular $\mathrm{O}_{2}$ Generation and Consumption. For $\mathrm{O}_{2}$ generation, [NPs] $=200$ $\mu \mathrm{g} / \mathrm{mL},\left[\mathrm{H}_{2} \mathrm{O}_{2}\right]=2 \mathrm{mM}$, and $[\mathrm{Glu}]=5 \mathrm{mM}$ were prepared. The real-time dissolved $\mathrm{O}_{2}$ concentration in $\mathrm{HMnO}_{2}-\mathrm{HA}, \mathrm{HMnO}_{2}-\mathrm{GOD}-\mathrm{HA}$ and $\mathrm{SiO}_{2}$-GOD-HA with various conditions was detected with an oxygen probe (JPBJ-608 portable Dissolved Oxygen Meters, Shanghai REX Instrument Factory).

MRI property. The aqueous solutions of $\mathrm{HMnO}_{2}-\mathrm{HA}$ nanoparticles at different $\mathrm{Mn}$ concentrations were mixed with GSH in the presence of $\mathrm{H}^{+}$or not for $15 \mathrm{~min}$, and then scanned by a $0.5 \mathrm{~T}$ NMR-analyzer (GY-PNMR-10). The parameters were set as follows: $\mathrm{TR}($ repetition time $)=100.0 \mathrm{~ms}, \mathrm{TE}($ echo time $)=8.6 \mathrm{~ms}, \mathrm{NS}($ number of scans $)=1$. The $r_{1}$ values were calculated from the slope of the curve-fitting result of $1 / T_{1}\left(\mathrm{~s}^{-1}\right)$ versus the Mn concentration (mM).

Photothermal performance. Different concentrations $(0-400 \mu \mathrm{g} / \mathrm{mL})$ of $\mathrm{HMnO}_{2^{-}}$ HA aqueous solutions were introduced in a quartz cuvette and irradiated with an 808 $\mathrm{nm}$ laser $\left(0.94 \mathrm{~W} / \mathrm{cm}^{2}\right)$ for $5 \mathrm{~min}$, and the temperature was recorded every $10 \mathrm{~s}$ by a thermocouple probe. The photothermal conversion efficiency of $\mathrm{HMnO}_{2}-\mathrm{HA}$ nanoparticles was calculated according to the previous method ${ }^{[2]}$. 


$$
\eta_{T}=\frac{h S\left(T_{\max }-T_{\text {surr }}\right)-Q_{d i s}}{I\left(1-10^{-A_{\lambda}}\right)}
$$

Where, $\eta_{\mathrm{T}}(100 \%)$ is the conversion efficiency from the absorbed light energy to thermal energy, $T_{\max }\left({ }^{\circ} \mathrm{C}\right)$ is the highest temperature of sample solution, $T_{\text {surr }}\left({ }^{\circ} \mathrm{C}\right)$ is ambient temperature of the surroundings, $Q$ dis $\left(\mathrm{J} \times \mathrm{S}^{-1}\right)$ is the baseline energy generated by quartz cell and water upon laser irradiation. $I(\mathrm{~W})$ is the laser power, $A_{\lambda}$ (dimensionless) is the absorbance of nanoparticles at the wavelength of $808 \mathrm{~nm} . h$ is the heat transfer coefficient, $S$ is the surface area of the container, hS can be obtained from substituting equation:

$$
\mathrm{hS}=\frac{m \times C_{\mathrm{H}_{2} \mathrm{O}}}{\tau_{s}}
$$

where $\mathrm{m}$ is the mass of solution, $\mathrm{C}_{2} \mathrm{O}$ is the heat capacity of water $\left(4.2 \mathrm{~J} \times \mathrm{g}^{-1} \times{ }^{\circ} \mathrm{C}^{-}\right.$ $\left.{ }^{1}\right) . \tau \mathrm{s}$ (dimensionless) is the sample system time constant, which can be obtained from the linear time data from the cooling period vs $-\ln \theta$ according to the following equation:

$$
\mathrm{t}=-\tau_{S} \ln \theta=-\tau_{S} \ln \left(\frac{T-T_{\text {surr }}}{T_{\max }-T_{\text {surr }}}\right)
$$

where $\mathrm{t}(\mathrm{s})$ is the time of cooling period, $\theta$ represents the dimensionless driving force temperature.

Drug releasing behavior. The DOX releasing investigation was performed by adding $\mathrm{HMnO}_{2}$-DOX-GOD-HA and Hyaluronidase in the dialysis bag (MWCO 14000) into different PBS medium at $37^{\circ} \mathrm{C}$ under continuous shaking. At given time intervals, $200 \mu \mathrm{L}$ of the release medium was taken out for UV-vis analysis at $480 \mathrm{~nm}$ to determine the released amount of DOX to further calculate the releasing efficiency.

Cell culture and CD44 expression detection. Human breast adenocarcinoma cell line MDA-MB-231 and human embryonic kidney cell line 293T were cultured in the 
DMEM with $10 \% \mathrm{FBS}, 100 \mathrm{IU} / \mathrm{mL}$ of penicillin and $100 \mu \mathrm{g} / \mathrm{mL}$ of streptomycin in an incubator under an atmosphere of $5 \% \mathrm{CO}_{2}$ at $37{ }^{\circ} \mathrm{C}$. The expressions of CD44 in MDAMB-231 and 293T cells were detected by immunofluorescence labeling and flow cytometry analysis.

In vitro targeting test. To compare cellular uptake in MDA-MB-231 and 293 T cell, FITC loaded $\mathrm{HMnO}_{2}$-FITC-HA and $\mathrm{HMnO}_{2}$-FITC-PAA nanoparticles were first prepared. MDA-MB-231 cells were co-incubated with targeting $\mathrm{HMnO}_{2}$-FITC-HA and non-targeting $\mathrm{HMnO}_{2}$-FITC-PAA, $293 \mathrm{~T}$ cells were co-incubated with $\mathrm{HMnO}_{2}$-FITCHA for $30 \mathrm{~min}$, respectively. And then, cells were fixed by treating with $4 \%$ paraformaldehyde and further stained with Hoechst 33342. Confocal laser scanning microscopy (CLSM) was used to observe the cellular uptake in each cell line. In addition, the cytotoxicity of $\mathrm{HMnO}_{2}$-HA nanoparticles for a short co-incubated time also evaluated in MDA-MB-231 and 293T cells by using a standard MTT assay. Cells were initially seeded in a 96-well cell culture plate at a density of $10^{4}$ cells per well for $24 \mathrm{~h}$ before $\mathrm{HMnO}_{2}$-HA with various concentrations in the medium were added into each well. After co-incubated for $30 \mathrm{~min}$, the medium containing nanoparticles were changed to fresh complete DMEM medium and further incubated for $24 \mathrm{~h}$. Then, $10 \mu \mathrm{L}$ of MTT ( $5 \mathrm{mg} / \mathrm{mL}$ in PBS solution) was added to the culture medium and incubation was carried out for another $4 \mathrm{~h}$. Subsequently, culture supernatants were removed and $150 \mu \mathrm{L}$ of DMSO was added to dissolve the purple formazan crystals. The absorbance was measured at $570 \mathrm{~nm}$ by a cell imaging microplate reader (Cytation 3, BioTek) and the cell viabilities were calculated from the OD value. 
Assessment of cell hypoxia. MDA-MB-231 cells were first seeded into cell culture plate for $20 \mathrm{~h}$ in normoxia $\left(21 \% \mathrm{O}_{2}\right)$ environment and then transferred to an extreme hypoxia $\left(1 \% \mathrm{O}_{2}\right)$ environment for the following experiments. Then, $\mathrm{HMnO}_{2}-\mathrm{HA}$ nanoparticles with different concentrations were added into MDA-MB-231 cells for 24 $\mathrm{h}$ in hypoxia. The cytotoxicity of $\mathrm{HMnO}_{2}$-HA under different atmosphere was measured by MTT assay. Furthermore, ROS-ID was used to evaluate intracellular hypoxia. After cultured in extreme hypoxia for $4 \mathrm{~h}$, MDA-MB-231 cells were treated with no-glucose medium containing $\mathrm{HMnO}_{2}$-HA , GOD-loaded $\mathrm{HMnO}_{2}$-GOD-HA and GOD-loaded $\mathrm{SiO}_{2}$-GOD-HA nanoparticles at an $\mathrm{Mn}$ concentration of $20 \mu \mathrm{g} / \mathrm{mL}$. After $4 \mathrm{~h}$ co-incubation, no-glucose mediums were changed to high-glucose complete DMEM medium and cultured for another $4 \mathrm{~h}$. Then, the MDA-MB-231 cells were stained with the ROS-ID hypoxia red detection probe and Hoechst33342 in hypoxia and then observed by CLSM. In addition, flow cytometry (FCM) was also used to determine the red fluorescence intensity in nanoparticles treated MDA-MB-231 cells, indicating the hypoxia level in MDA-MB-231 cells.

Western blotting analysis of Glut1. After cultured in hypoxia for 4 h, MDA-MB-231 cells were treated with $\mathrm{HMnO}_{2}$-GOD-HA and $\mathrm{SiO}_{2}$-GOD-HA nanoparticles in hypoxia for $8 \mathrm{~h}$ to evaluate the influence of $\mathrm{HMnO}_{2}$-GOD-HA on Glut1 expression. The cells in each well were lysed and centrifuged. Total proteins in the supernatant were quantified by BCA protein assay kit. 10\% SDS- polyacrylamide gels and protein loading buffer were used to separate the denatured proteins after boiling the proteins. Then, separated proteins were electrotransferred onto polyvinylidene fluoride membrane and stained 
with ponceau. The protein ladder in the membrane was cut into pieces according to the staining indication and blocked with 5\% skim milk in TBST. And then, the primary antibody was added into the membrane and incubated overnight in $4{ }^{\circ} \mathrm{C}$. After washing the membrane with TBST 3 times, the secondary antibody was added and incubated for another $2 \mathrm{~h}$ at room temperature. At last, ECL mix reagent was added and the membrane was imaged using a gel imaging system.

Cellular uptake and co-localization of DOX-loaded nanoparticles. The internalization of $\mathrm{HMnO}_{2}$-DOX-GOD-HA nanoparticles in MDA- MB-231 cells were observed by CLSM. In brief, MB-MDA-231 cells were incubated with $\mathrm{HMnO}_{2}$-DOXGOD-HA nanoparticles for 12 and $24 \mathrm{~h}$ in the confocal laser dish, then, cells were washed and stained with Lysotracker Green $(250 \mathrm{nM})$ and Hoechst $33342(10 \mu \mathrm{g} / \mathrm{mL})$. The distribution of $\mathrm{HMnO}_{2}$-DOX-GOD-HA nanoparticles and released DOX and colocalization with lysosome were observed by a Leica TCS SP5 CSLM.

Intracellular reactive oxygen generation. DCFH-DA was selected as the probe to detect intracellular reactive oxygen (ROS) generation in MDA-MB-231 cells. After the treatments of $\mathrm{HMnO}_{2}-\mathrm{HA}, \quad \mathrm{HMnO}_{2}$-GOD-HA and $\mathrm{HMnO}_{2}$-DOX-GOD-HA nanoparticles at the same Mn concentration of $20 \mu \mathrm{g} / \mathrm{mL}$ with or without an $808 \mathrm{~nm}$ laser irradiation $\left(0.94 \mathrm{~W} / \mathrm{cm}^{2}, 5 \mathrm{~min}\right)$ for $12 \mathrm{~h}$, DCFH-DA solution was added to MDAMB-231 cells and cultured for another $30 \mathrm{~min}$. Subsequently, the fluorescence images were obtained by a Nikon Eclipse Ti fluorescence microscope, and the quantitative analysis of fluorescence intensity of DCF in cells were measured by flow cytometry. 
In Vitro synergistic therapy. After the cultivation of MDA-MB-231 cells into the 96well plates for $24 \mathrm{~h}$, the cells were treated with glucose-free medium containing free DOX, $\mathrm{HMnO}_{2}$-DOX-HA and $\mathrm{HMnO}_{2}$-DOX-GOD-HA nanoparticles at equal concentrations of DOX and incubated for another $4 \mathrm{~h}$. Then, the culture medium was refreshed with high-glucose complete DMEM medium, and the cells were incubated without NIR laser irradiation for another $20 \mathrm{~h}$. For the NIR group, the $\mathrm{HMnO}_{2}$-DOXGOD-HA treated cells were irradiated by an $808 \mathrm{~nm}$ laser for $5 \mathrm{~min}$ after refreshing the complete medium for $4 \mathrm{~h}$. After irradiation, these cells were put back into the incubator for $16 \mathrm{~h}$. Then, the standard MTT assay was carried out to calculated the cell viability for all groups.

For the live/dead cell staining assay, MDA-MB-231 cells were seeded into a 24-well culture plate and cultured for $24 \mathrm{~h}$. Then, the medium was replaced with the fresh glucose-free medium containing $\mathrm{HMnO}_{2}$ - $\mathrm{HA}, \mathrm{HMnO}_{2}$-GOD-HA and $\mathrm{HMnO}_{2}$-DOXGOD-HA at the Mn concentration of $20 \mu \mathrm{g} / \mathrm{mL}$. After $4 \mathrm{~h}$, the previous medium was replaced with fresh high-glucose complete DMEM medium and cultured for another 4 h. After that, for NIR groups, the cells were irradiated with an $808 \mathrm{~nm}$ laser for $5 \mathrm{~min}$. Then, all cells were cultured for another $18 \mathrm{~h}$. Furthermore, cells were stained with a mixed solution of calcein AM (live, green fluorescence) and PI (dead, red fluorescence) for 20 min. Finally, the cells were washed with PBS and imaged by CLSM.

For apoptosis analysis, MDA-MB-231 cells were seeded into a 24-well culture plate for $24 \mathrm{~h}$. Then, the following operation was performed as above mentioned, cells were incubated with different samples and further irradiated with $808 \mathrm{~nm}$ laser. After 
incubation for a total $24 \mathrm{~h}$, the cells were centrifuged and washed with PBS twice, then the cells were resuspended in annexin $\mathrm{V}$ binding buffer. Then, the cells were stained with annexin V-FITC for and PI for $15 \mathrm{~min}$ in the dark. Finally, cells were filtered through a 300-mesh filter and analyzed by a FACS Calibur flow cytometer (BD Bioscience).

Animal tumor model. All live animal experiments were conducted according to the Institutional Animal Care and Use Committee of the Chinese Academy of Sciences and the Regulations for the Administration of Affairs Concerning Experimental Animals. The tumor model was built by a subcutaneous injection of $150 \mu \mathrm{L}$ of MDA-MB-231 cells $\left(2.5 \times 10^{7}\right.$ cells $)$ in the right armpit of female athymic nude mice (6 weeks old). Tumor-bearing mice used for imaging and therapy had a tumor volume of up to $\sim 100$ $\mathrm{mm}^{3}$.

In vivo $T_{1}$-Weighted MR Imaging. Firstly, the tumor-bearing mice were anesthetized via intraperitoneal injection of $24 \%$ urethane solution followed by fixing into an animal handing system and scanned before treating with nanoparticles. After receiving an intratumor administration with $\mathrm{HMnO}_{2}$ - $\mathrm{HA}$ nanoparticles $(4 \mathrm{mg} / \mathrm{kg}$ of $\mathrm{Mn}$ concentration), three randomly chosen tumor-bearing mice underwent in vivo MR imaging study using a $1.5 \mathrm{~T}$ small animal magnetic resonance imager at $35^{\circ} \mathrm{C}$. Then, MR images were sequentially obtained at $2,10,24$ and $72 \mathrm{~h}$ after injection. In vivo $\mathrm{T}_{1^{-}}$ weighted images were acquired using a spin echo sequence with the following parameters: $\mathrm{TR} / \mathrm{TE}=100 \mathrm{~ms} / 14.12 \mathrm{~ms}$, matrix $=512 \times 256, \mathrm{FOV}=80 \times 45 \mathrm{~mm}$, and slice thickness $=0.35 \mathrm{~mm}$. 
In Vivo Photothermal Imaging. The tumor-bearing mice were intratumorally injected with saline and $\mathrm{HMnO}_{2}$-DOX-GOD-HA nanoparticles, respectively. After $12 \mathrm{~h}$, a visual IR thermometer (Fluke Corporation) was applied to detect the temperature change of tumor under laser irradiation every minute.

In Vivo Antitumor Study. The tumor-bearing mice were randomly divided into seven groups $(n=3)$ : saline, free DOX, $\mathrm{HMnO}_{2}-\mathrm{HA}+\mathrm{NIR}, \mathrm{HMnO}_{2}-\mathrm{GOD}-\mathrm{HA}+\mathrm{NIR}, \mathrm{HMnO}_{2}-$ DOX-HA+NIR, $\mathrm{HMnO}_{2}$-DOX-GOD-HA and $\mathrm{HMnO}_{2}$-DOX-GOD-HA+NIR. MDAMB-231 tumor-bearing mice were intratumorally injected with above-mentioned nanoparticles at Mn concentration of $4 \mathrm{mg} / \mathrm{kg}$ and DOX concentration of $5.6 \mathrm{mg} / \mathrm{kg}$ at $1^{\text {st }}$ and $4^{\text {th }}$ day, respectively. After administration for $12 \mathrm{~h}$, mice were irradiated with an $808 \mathrm{~nm}$ laser for $5 \mathrm{~min}$ at a power density of $0.94 \mathrm{~W} / \mathrm{cm}^{2}$. At given interval time points, the tumor volumes (length $\times$ width $\left.^{2} \times 0.5\right)$ and body weight of mice were recorded. After 21 days, the mice were sacrificed, ex vivo tumors were weighted and photographed, followed by collecting major organs and tumors for further histological analysis.

Immunohistochemistry. For histological analysis, the major organs and tumors were successively dehydrated using buffered formalin, ethanol, and xylene. Then the dehydrated tissues were embedded in liquid paraffin and sliced to $5 \mathrm{~mm}$ thickness for hematoxylin and eosin (H\&E) staining. The final slices were imaged with an optical microscope. Moreover, the tumor tissues were sliced for heat shock protein 70 (HSP70), hypoxia inducible factor $1 \alpha(\mathrm{HIF}-1 \alpha)$ and ROS immunofluorescence staining, terminal deoxynucleotidyl transferase dUTP nick end labeling (TUNEL) staining to investigate 
the modulation effect of nanoparticles on tumor hypoxia in vivo, cell apoptosis and the antitumor mechanism.

Statistical Significance. Data were presented as Mean \pm SD values. The statistical analysis was carried out with graph pad prism software, and the statistical significance was calculated using t-test and analysis of variance (ANOVA; one-way or two-way). The corresponding P-values are added in the figures and figure legends. 


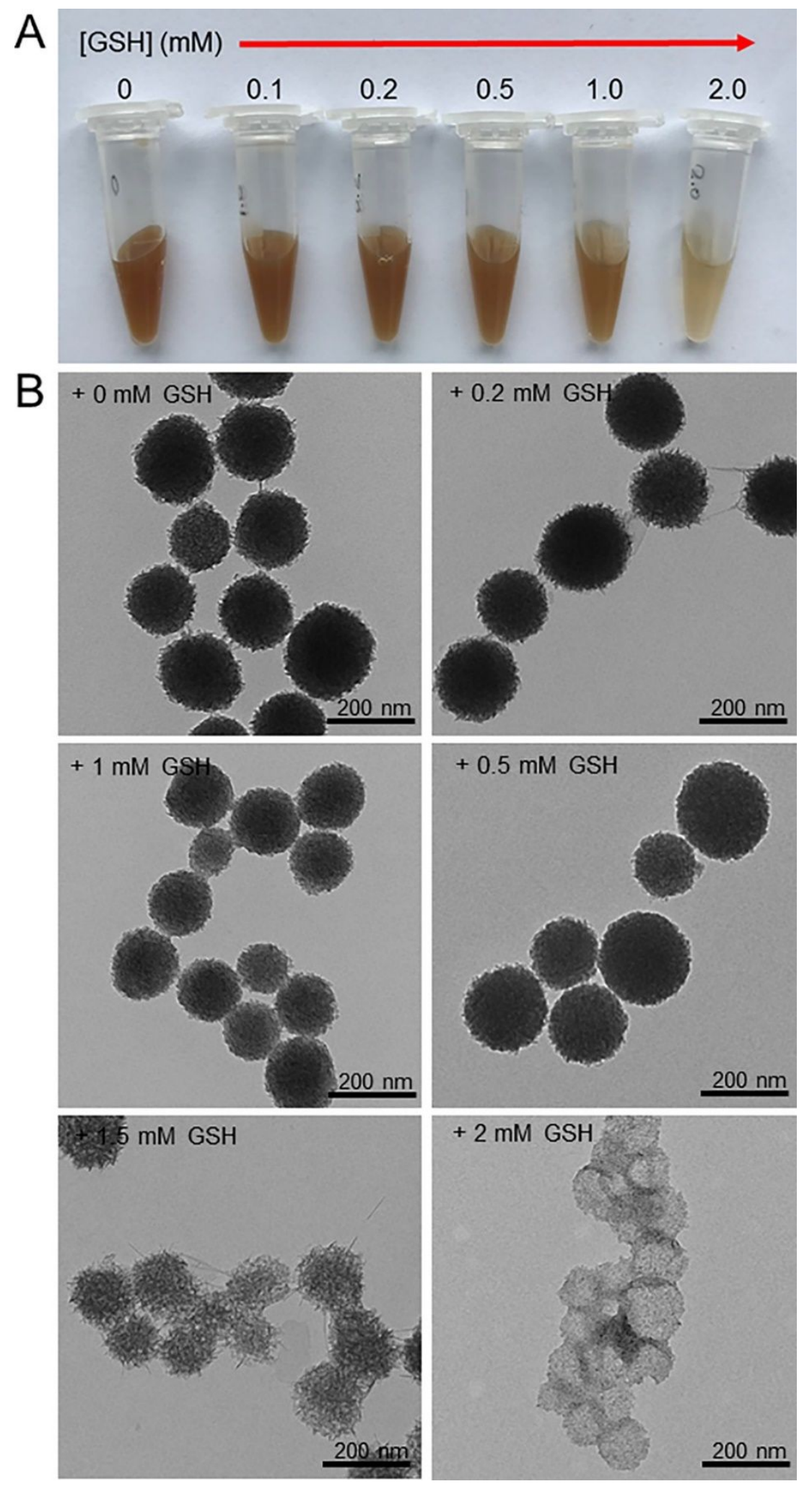

Figure S1. (A) Digital photographs and corresponding (B) TEM images of PDA@ $\mathrm{MnO}_{2}$ NPs after exposure to different concentrations of GSH at $\mathrm{pH} 6$ for 5 min. The scale bar is $200 \mathrm{~nm}$. 

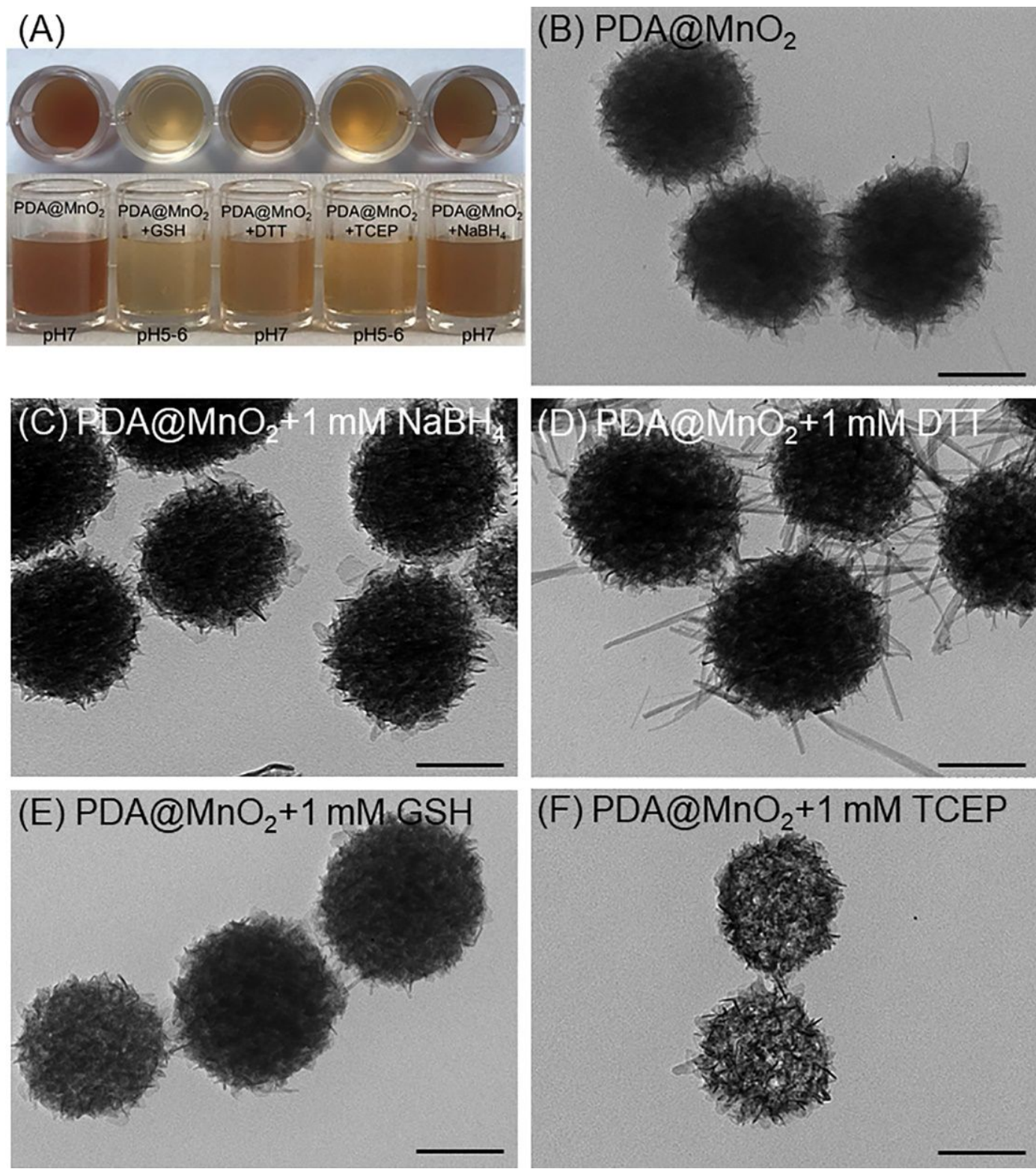

Figure S2. (A) Digital photograph and corresponding (B-F) TEM images of PDA@MnO2 nanoparticles $(200 \mu \mathrm{g} / \mathrm{mL})$ treated with $1 \mathrm{mM}$ different reducing agents and acidity for $30 \mathrm{~min}$. The scale bar is $100 \mathrm{~nm}$. 

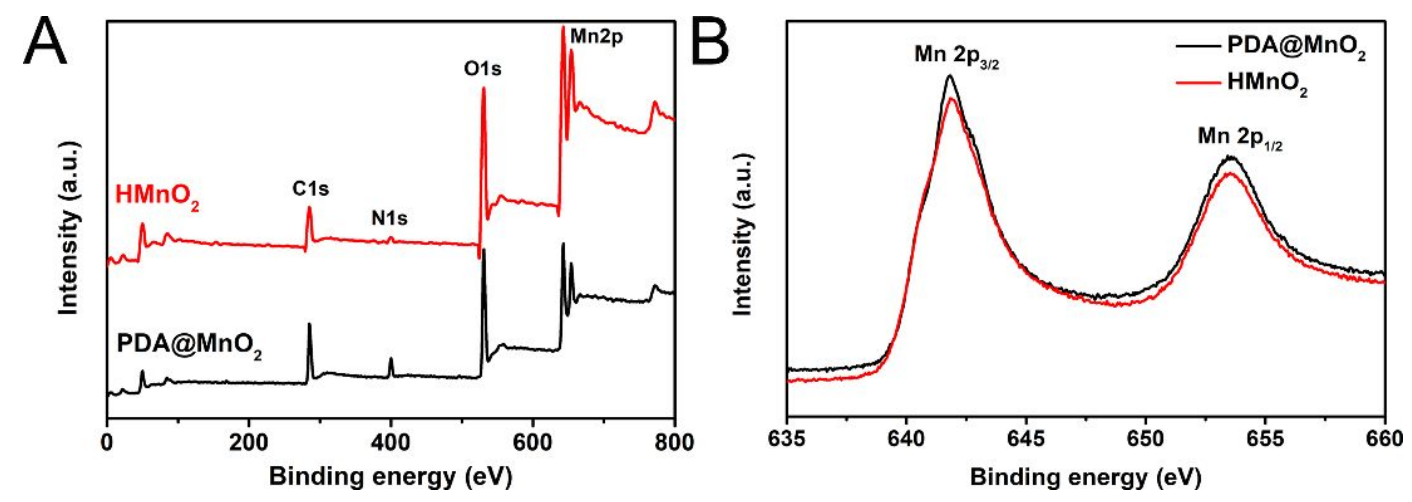

Figure S3. (A) XPS spectra and (B) high resolution Mn 2p XPS spectra of $\mathrm{PDA} @ \mathrm{MnO}_{2}$ and $\mathrm{HMnO}_{2}$ nanoparticles.
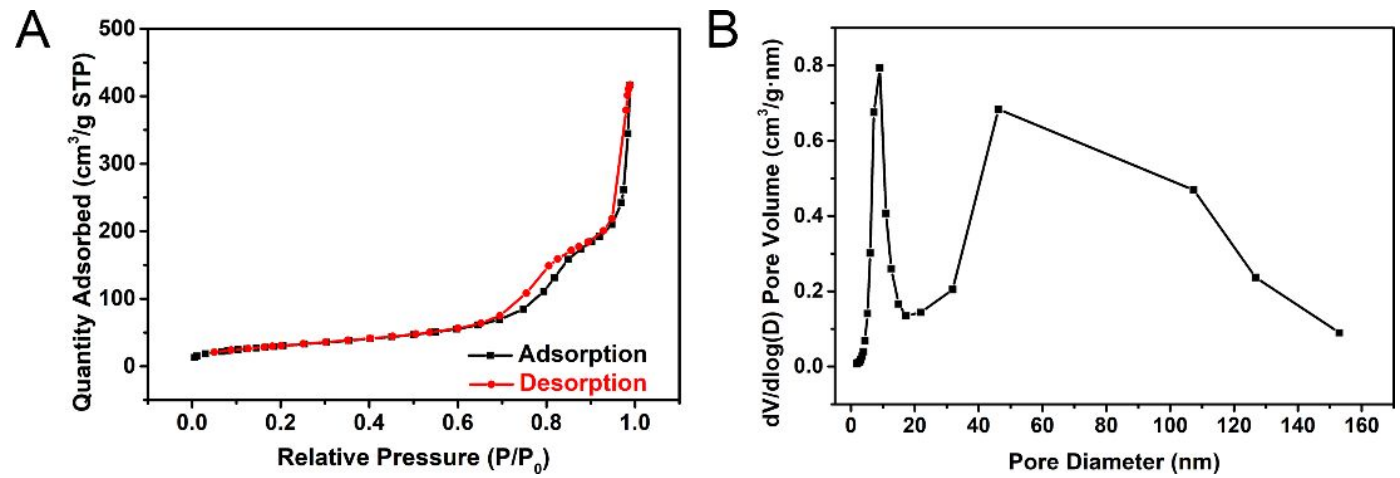

Figure S4. (A) $\mathrm{N}_{2}$ absorption-desorption isotherms and (B) corresponding pore-size distribution of the $\mathrm{HMnO}_{2}$ nanoparticles. 


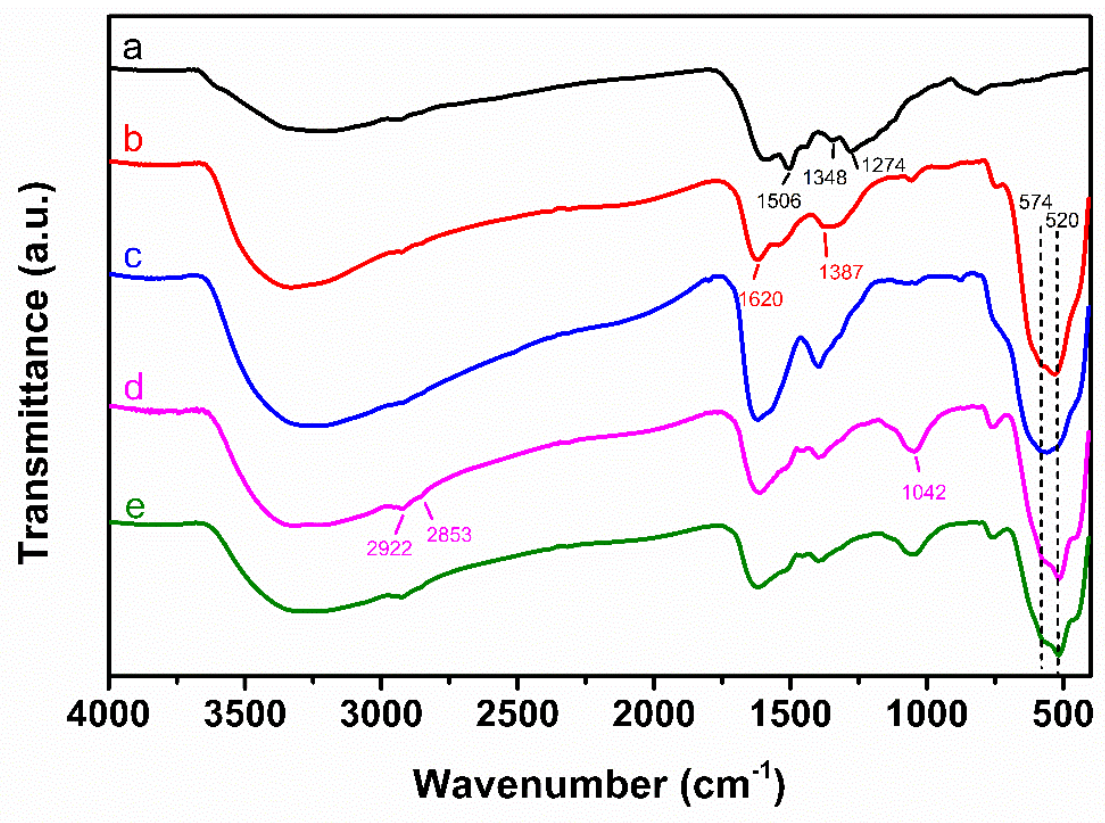

Figure S5. FT-IR spectrum of a) PDA, b) PDA@ $\mathrm{MnO}_{2}$, c) $\mathrm{HMnO}_{2}$, d) $\mathrm{HMnO}_{2}-\mathrm{HA}$ and e) $\mathrm{HMnO}_{2}$-GOD-HA nanoparticles.

Fourier-transform infrared spectroscopy (FT-IR) was carried out with a Bruker Hyperion Vertex 80 spectrometer to analyze the preparation process and samples. As shown in figure S5, the original PDA characteristic peaks located at 1507, 1348 and $1274 \mathrm{~cm}^{-1}$, representing the $\mathrm{C}=\mathrm{N}, \mathrm{C}-\mathrm{N}-\mathrm{C}$ and $\mathrm{C}-\mathrm{N}$ stretching vibration, respectively, have decreased and the peak at 574 and $520 \mathrm{~cm}^{-1}$ confirm the oxidation of the PDA and the formation of $\mathrm{MnO}_{2} \cdot{ }^{[3]}$ In the spectrum of $b-e$, the peaks between 400 and $700 \mathrm{~cm}^{-1}$ could be assigned to $\mathrm{Mn}-\mathrm{O}$ bending vibrations, which are related to the vibration mode of the $\mathrm{MnO}_{6}$ octahedron. The broad peak around $3400 \mathrm{~cm}^{-1}$ is believed to be associated with the stretching vibrations of hydrogen-bonded surface water molecules and hydroxyl groups and the bands at about 1620 and $1398 \mathrm{~cm}^{-1}$ are attributed to bending vibrations of the $\mathrm{OH}$ group, related to adsorbed and crystalline water molecules present. After removing the PDA core, the peaks at 1544 and $744 \mathrm{~cm}^{-1}$ assigning to the amide 
II and C-H groups have disappeared, however, the peaks around 1620 and $1400 \mathrm{~cm}^{-1}$ still be kept, representing that $\mathrm{HMnO}_{2}$ has similar surface groups with PDA@ $\mathrm{MnO}_{2}$. In the spectra of $\mathrm{HMnO}_{2}-\mathrm{HA}$, it can be found that the characteristic peaks at $1042 \mathrm{~cm}^{-1}$ due to the $\mathrm{C}-\mathrm{O}-\mathrm{C}$ hemiacetalic system saccharide units of hyaluronic acid. ${ }^{[4]}$ In addition, the peaks at 2922 and $2853 \mathrm{~cm}^{-1}$ corresponding to C-H symmetric stretching vibration are also observed. There is no obvious difference in the FT-IR spectrum of $\mathrm{HMnO}_{2}$ and GOD-loaded $\mathrm{HMnO}_{2}$-GOD-HA nanoparticles, it means GOD loading does not affect the layer-by-layer procedure.

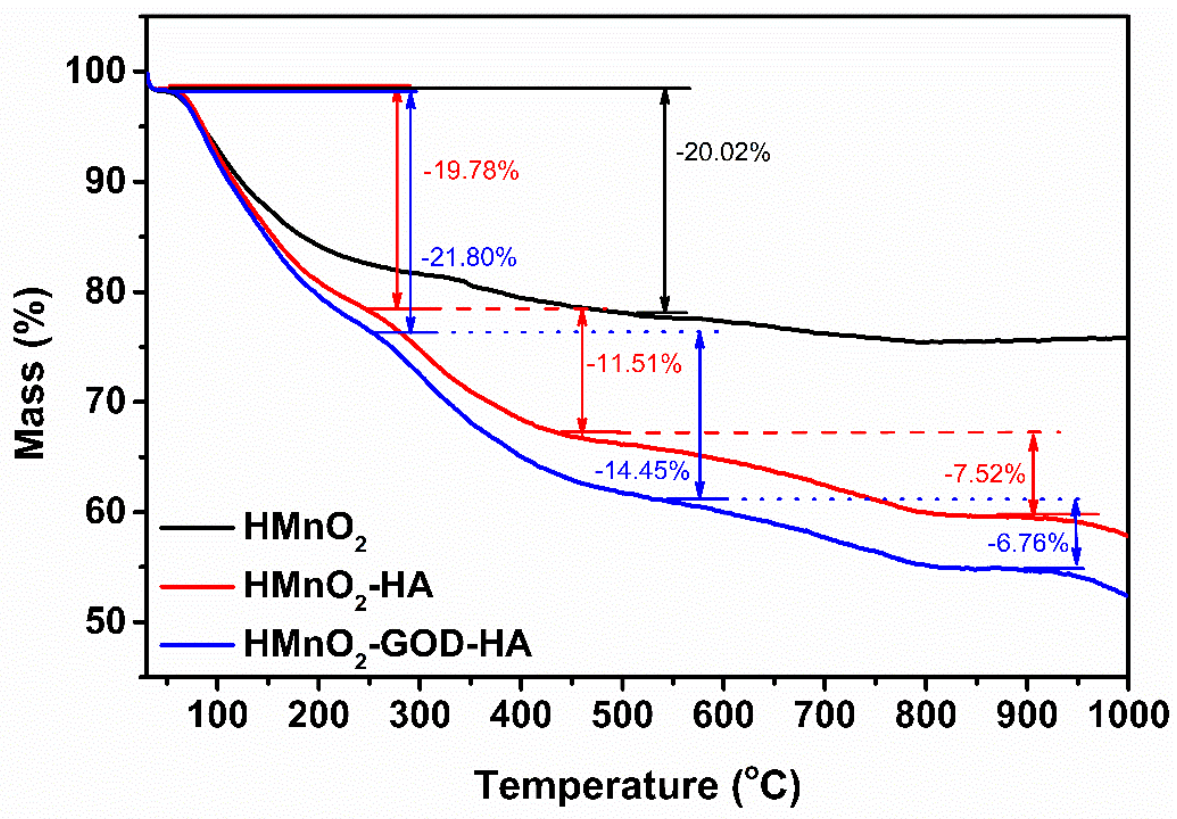

Figure S6. TGA curves of $\mathrm{HMnO}_{2}, \mathrm{HMnO}_{2}-\mathrm{HA}$ and $\mathrm{HMnO}_{2}-\mathrm{GOD}-\mathrm{HA}$ over the temperature range from 30 to $1000{ }^{\circ} \mathrm{C}$.

Thermogravimetric analysis (TGA) was carried out at temperatures ranging from 30 to $1000{ }^{\circ} \mathrm{C}$ under $\mathrm{N}_{2}$ atmosphere with a Netzsch STA 449F3 instrument. As shown in Figure S6, the TG curve of $\mathrm{HMnO}_{2}$ is similar to the reported polydopamine 
nanoparticles, ${ }^{[5]}$ which proved the residual PDA components in the hollow $\mathrm{HMnO} 2$ nanoparticles. Moreover, the weight of residual PDA in $\mathrm{HMnO} 2$ was calculated about $20.02 \%$. According to the decomposition temperature of HA (around $225^{\circ} \mathrm{C}$ ) ${ }^{[6]}$ and GOD (around $330^{\circ} \mathrm{C}$ ) ${ }^{[7]}$, the weight ratio of $\mathrm{HA}$ in $\mathrm{HMnO}_{2}-\mathrm{HA}$ was about $18.79 \%$ and the loading efficiency of GOD into the $\mathrm{HMnO}_{2}$-GOD-HA was $2.12 \%$.
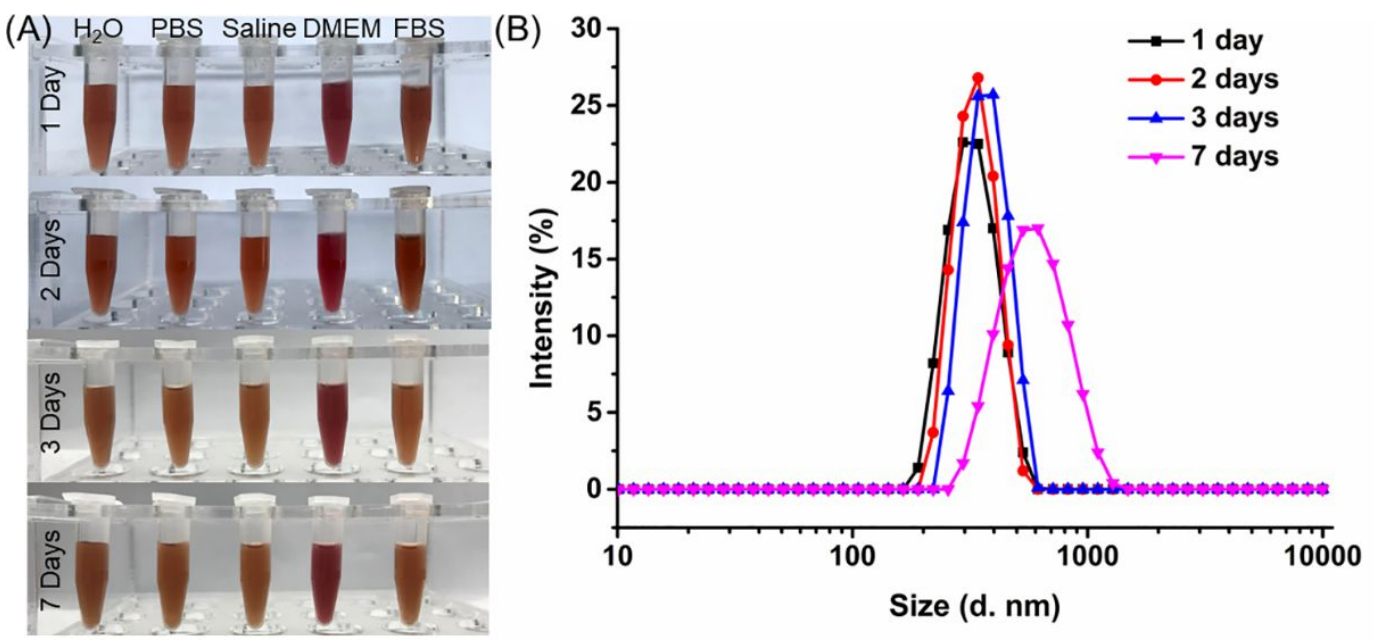

Figure S7. (A) Digital Photographs of time-dependent $\mathrm{HMnO}_{2}-\mathrm{DOX}-\mathrm{GOD}-\mathrm{HA}$ nanoparticles stability in different environments: ultrapure water, PBS buffer, $9 \%$ saline solution, DMEM and FBS. (B) DLS measurement shows stability of HMnO2-DOXGOD-HA nanoparticles dispersed in complete medium (DMEM+10\%FBS).
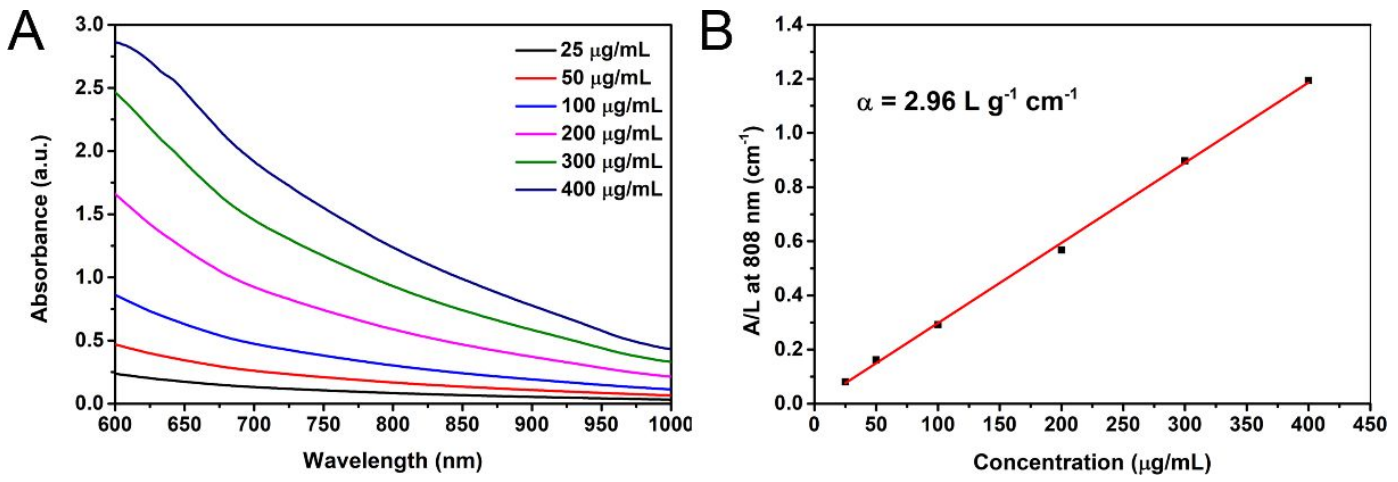
Figure S8. (A) Absorption spectra of $\mathrm{HMnO}_{2}$ nanoparticles at varied concentrations in vis-NIR region and (B) the fitting curve of the absorbance of $\mathrm{HMnO}_{2}$ aqueous dispersions at $808 \mathrm{~nm}$ as a function of $\mathrm{HMnO}_{2}$ concentrations.
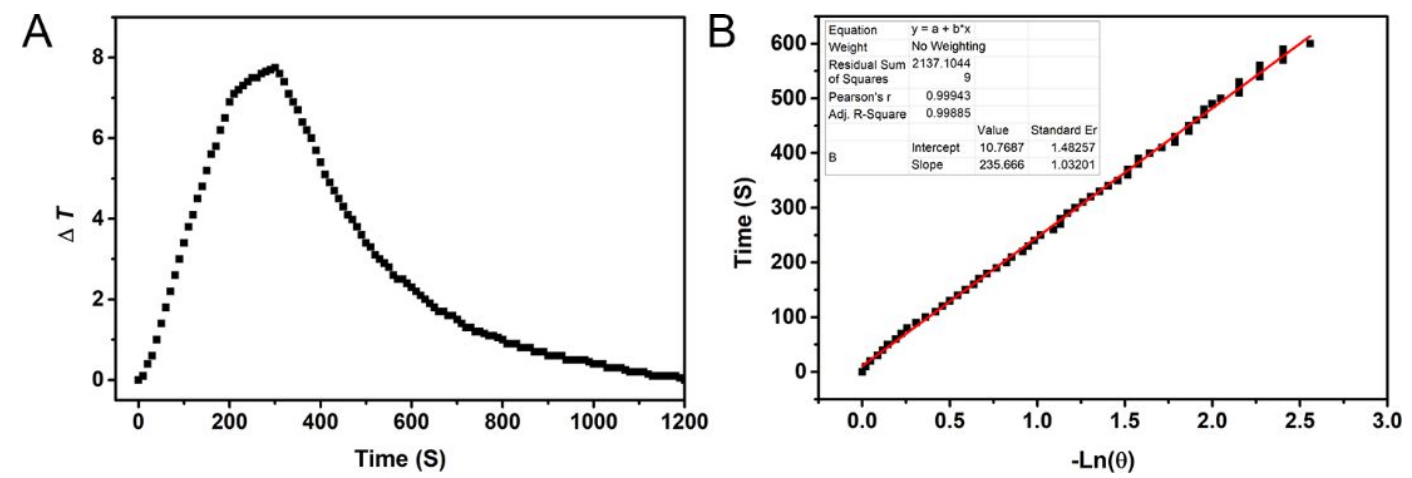

Figure S9. (A) The photothermal response of $\mathrm{HMnO}_{2}-\mathrm{HA}$ aqueous solution (200 $\mu \mathrm{g} / \mathrm{mL})$ for $300 \mathrm{~s}$ with a NIR laser $\left(808 \mathrm{~nm}, 0.94 \mathrm{~W} / \mathrm{cm}^{2}\right)$ and then the laser was shut off. (B) Linear time data versus - $\ln \theta$ obtained from the cooling period of (A).
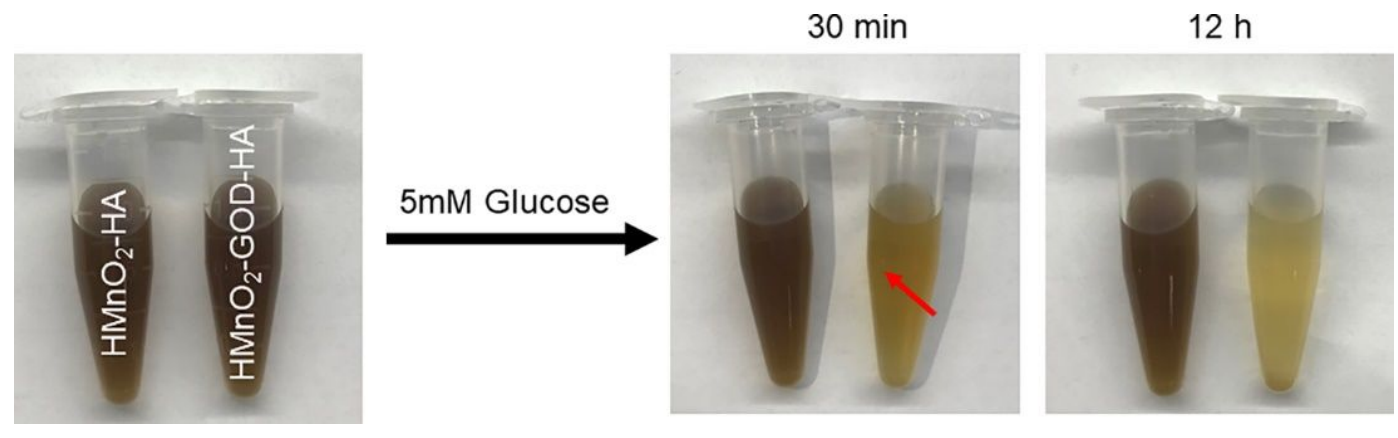

Figure S10. The photographs of decomposed procedure of $\mathrm{HMnO}_{2}-\mathrm{HA}$ and $\mathrm{HMnO}_{2^{-}}$ GOD-HA in $5 \mathrm{mM}$ glucose solution, showing the catalytic performance of GOD to glucose (The $\mathrm{O} 2$ bubble generated in $\mathrm{HMnO}_{2}-\mathrm{GOD}-\mathrm{HA} /$ Glucose is marked by the red arrows.). 


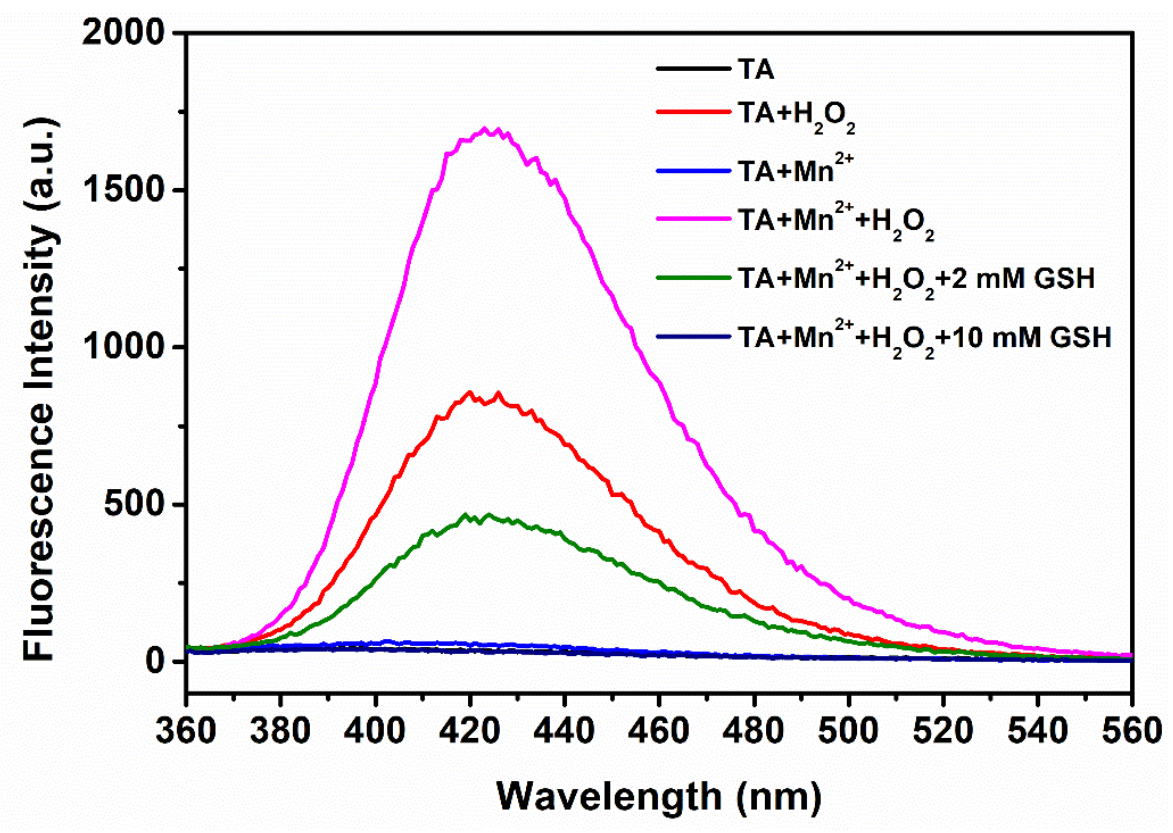

Figure S11. Terephthalic acid reacts with $\bullet \mathrm{OH}$ to form 2-hydroxy terephthalic acid (HTA), which exhibits fluorescence emission at $425 \mathrm{~nm}$. The fluorescence spectra of the HTA solutions resulting from the reactions of TA with $\mathrm{Mn}^{2+}$ and $\mathrm{H}_{2} \mathrm{O}_{2}$, and further treated with 2 and $10 \mathrm{mM} \mathrm{GSH}$. The reaction buffer: $25 \mathrm{mM} \mathrm{NaHCO} / 5 \% \mathrm{CO}_{2},[\mathrm{Mn}]$ $=0.5 \mathrm{mM},\left[\mathrm{H}_{2} \mathrm{O}_{2}\right]=8 \mathrm{mM}$ and $[\mathrm{TA}]=0.65 \mathrm{mM}$.
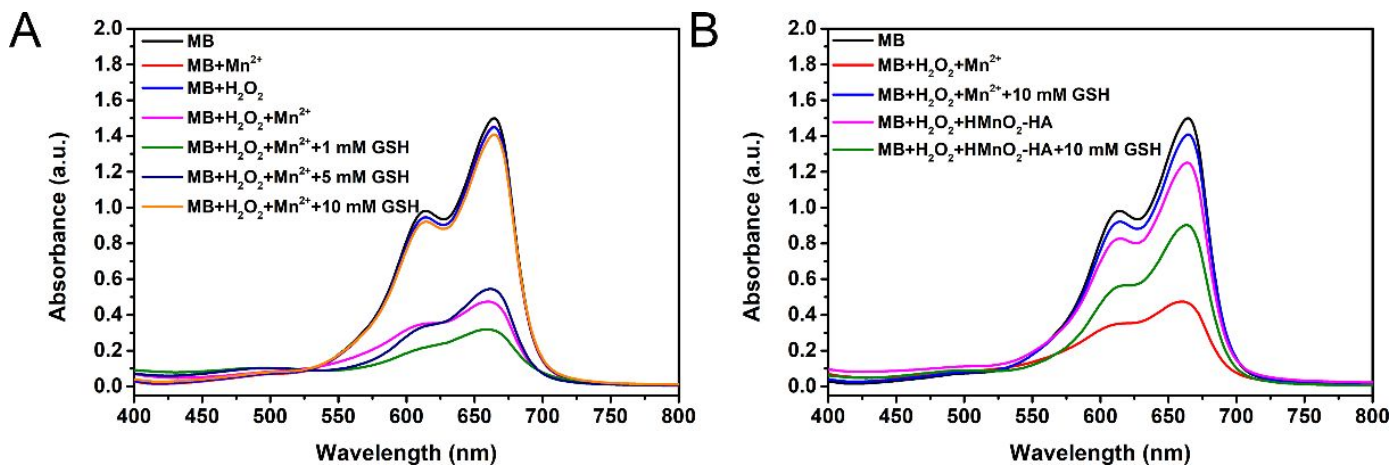

Figure S12. (A) UV-Vis absorption spectra of $\mathrm{MB}$ degradation by $\mathrm{H}_{2} \mathrm{O}_{2}$ and $\mathrm{Mn}^{2+}$, and further treated with different concentration of GSH. (B) UV-Vis absorption spectra of MB degradation by $\mathrm{H}_{2} \mathrm{O}_{2}$ plus $10 \mathrm{mM} \mathrm{GSH}$-treated $\mathrm{Mn}^{2+}$ or $\mathrm{HMnO}_{2}-\mathrm{HA}$ nanoparticles. The reaction buffer: $25 \mathrm{mM} \mathrm{NaHCO} 3 / 5 \% \mathrm{CO}_{2},[\mathrm{Mn}]=0.5 \mathrm{mM},\left[\mathrm{H}_{2} \mathrm{O}_{2}\right]=8 \mathrm{mM}$ and $[\mathrm{MB}]=10 \mu \mathrm{g} / \mathrm{mL}$. 

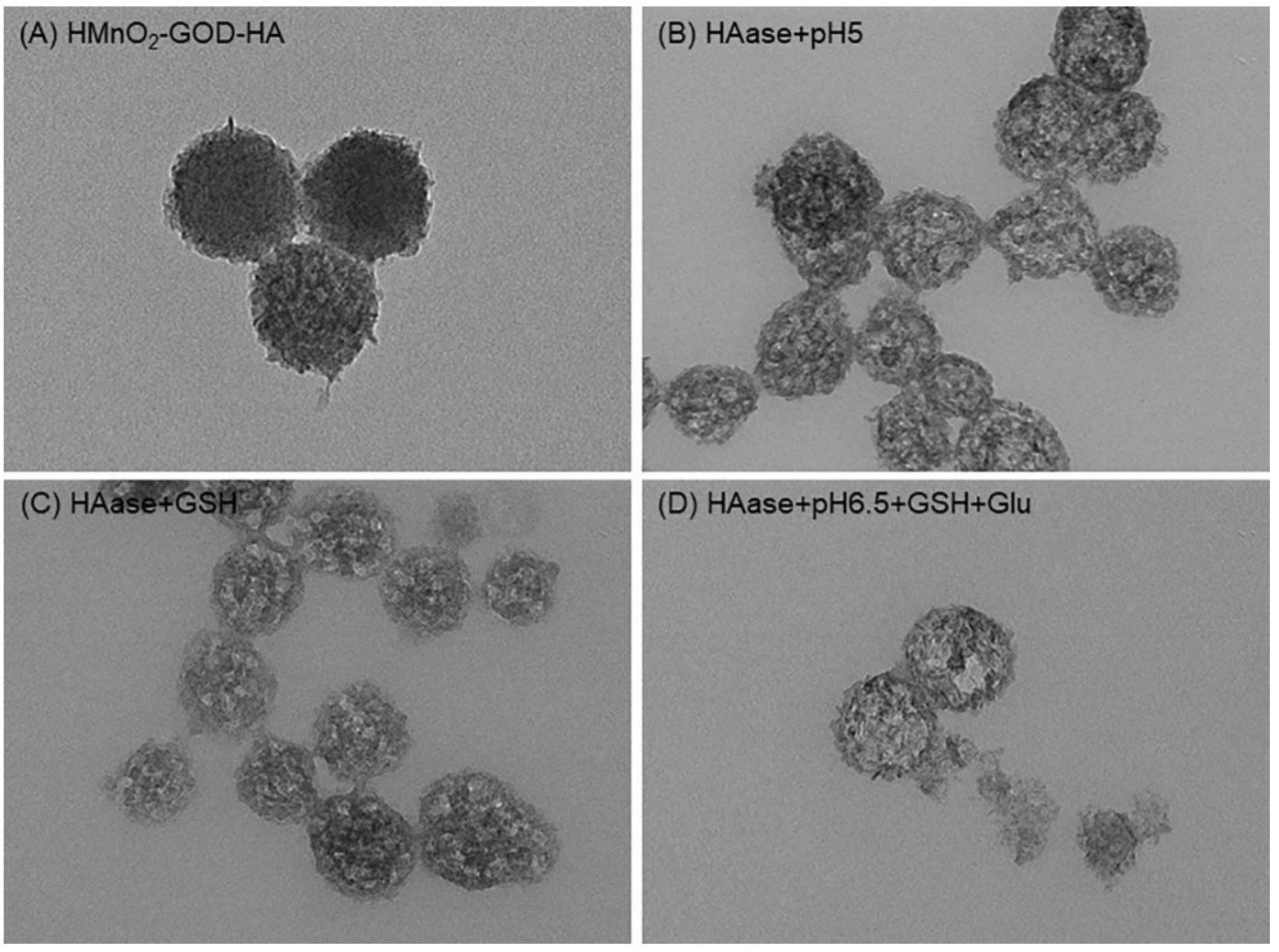

Figure S13. TEM images of $\mathrm{HMnO}_{2}-\mathrm{GOD}-\mathrm{HA}$ nanoparticles treated with (A) PBS (pH 7.4), (B) HAase + pH 5, (C) HAase $+2 \mathrm{mM} \mathrm{GSH}$ and (D) HAase $+\mathrm{pH} 6.5+2 \mathrm{mM}$ $\mathrm{GSH}+0.5 \mathrm{mg} / \mathrm{mL}$ glucose for $12 \mathrm{~h}$, showing the degradation of $\mathrm{HMnO}_{2}$-GOD-HA nanoparticles. 
(A)

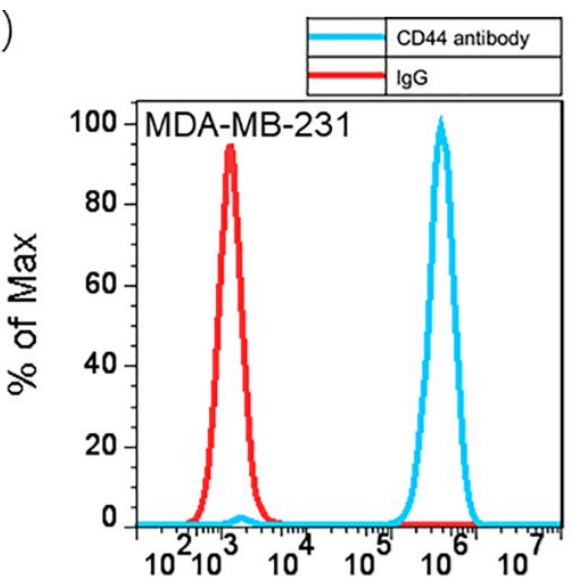

FL1-H:: FL1-H
(B)

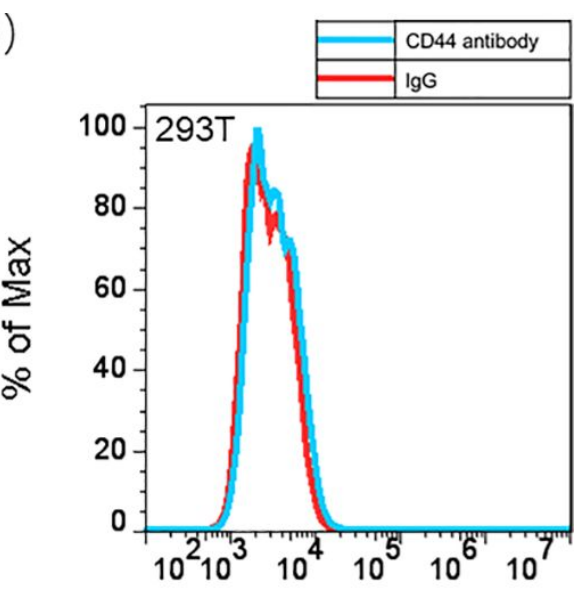

FL1-H:: FL1-H

Figure S14. Flow cytometry analysis of cell surface CD44 expression in (A) MDAMB-231 and (B) 293T cell lines.

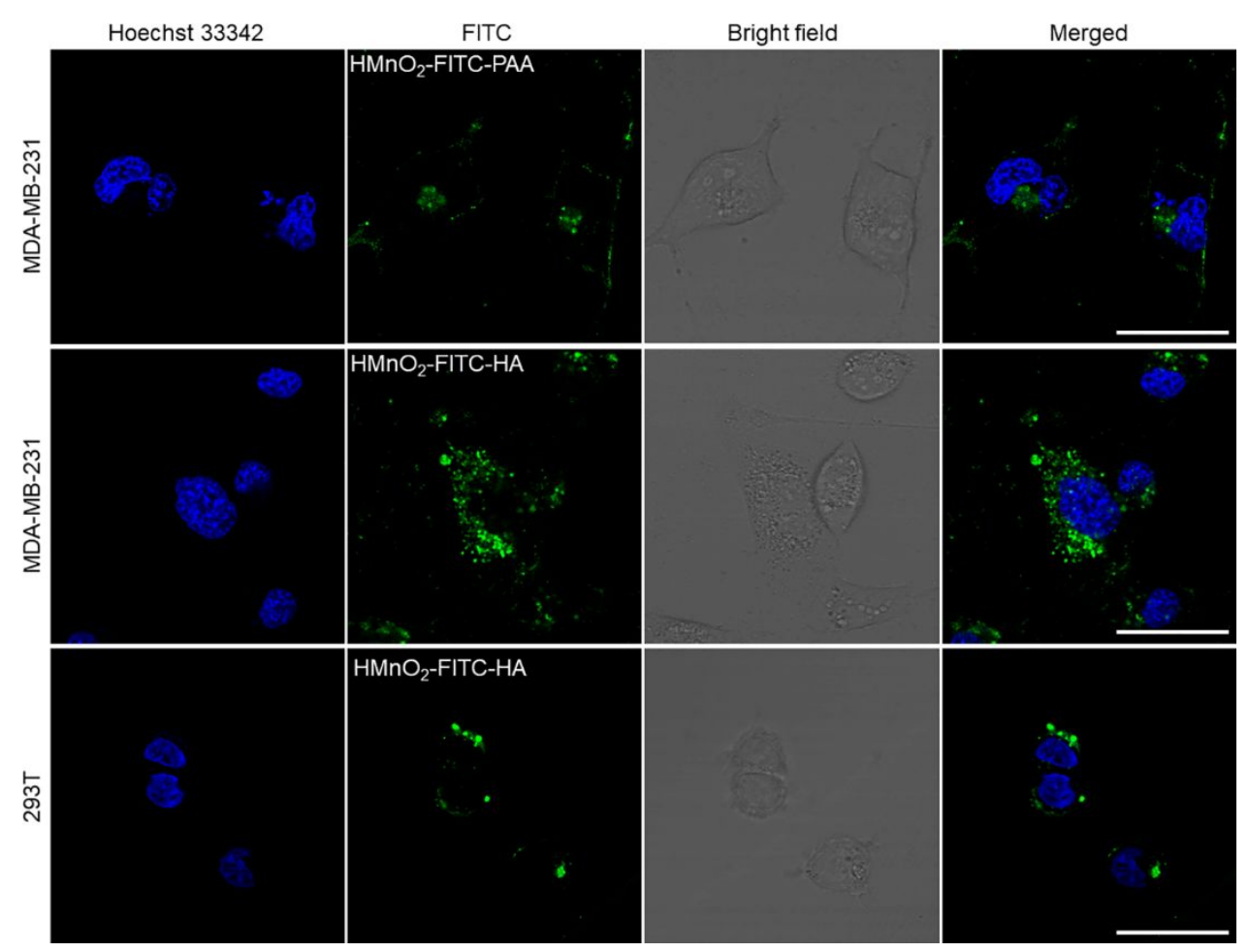

Figure S15. CLSM images of MDA-MB-231 and 293T cells treated targeting $\mathrm{HMnO}_{2-}$ FITC-HA or nontargeting for $30 \mathrm{~min}$. Cell nuclei were stained by Hoechst33342 for blue fluorescence while the green dots around the nucleus are the FITC labeled NPs. Scale bar $=40 \mu \mathrm{m}$. 


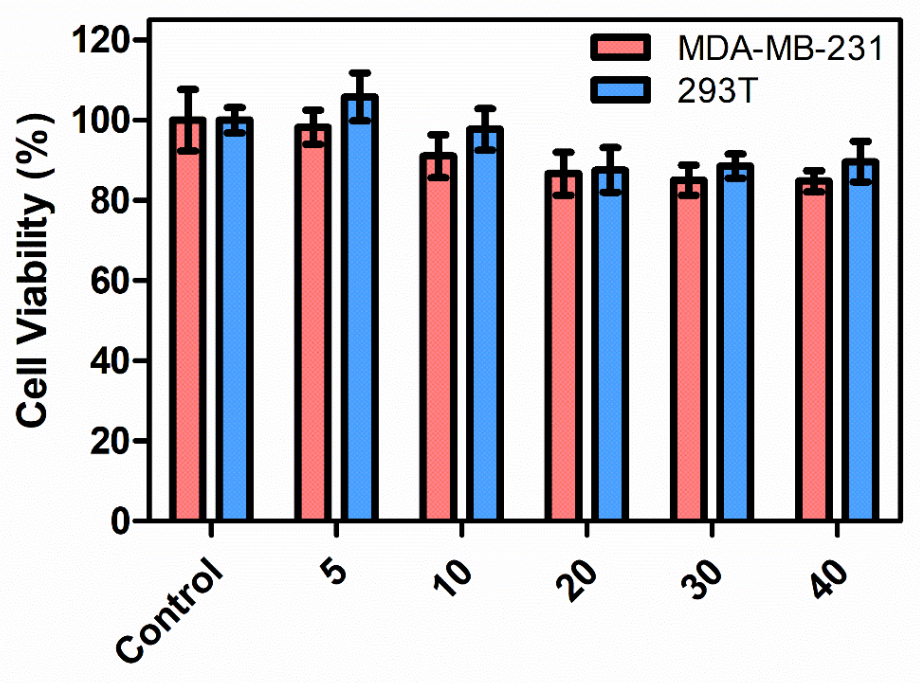

Mn Concentration $(\mu \mathrm{g} / \mathrm{mL})$

Figure S16 Cell viabilities of MDA-MB-231 and 293T cells. Cells were first coincubated with $\mathrm{HMnO}_{2}$-HA for 30 min and then changed with fresh media for another $24 \mathrm{~h}$ incubation. 

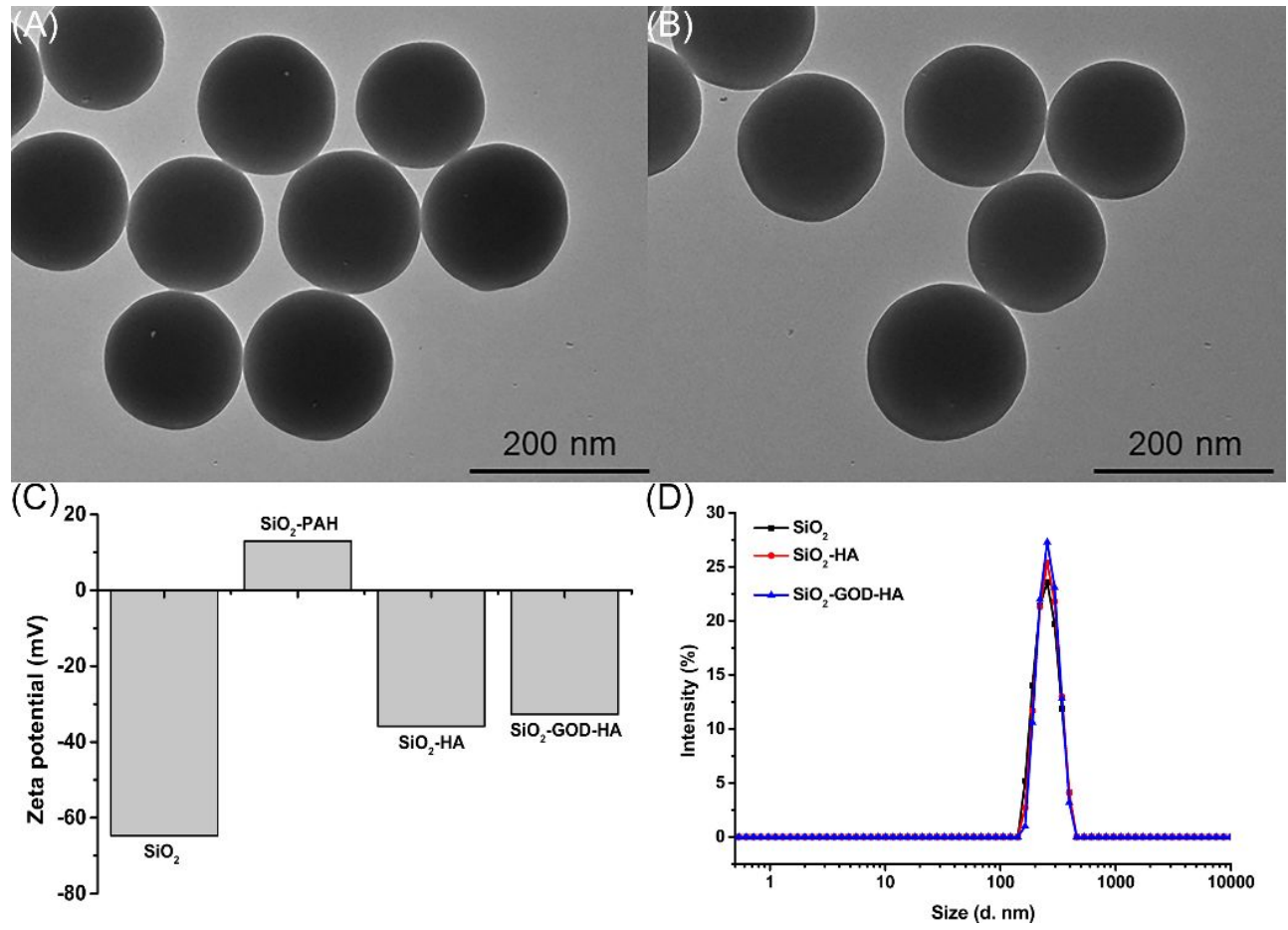

Figure S17. TEM images of (A) $\mathrm{SiO}_{2}$ and (B) $\mathrm{SiO}_{2}-\mathrm{GOD}-\mathrm{HA}$ nanoparticles. (C) Zeta potential of $\mathrm{SiO}_{2}, \mathrm{SiO}_{2}-\mathrm{PAH}, \mathrm{SiO}_{2}-\mathrm{HA}$ and $\mathrm{SiO}_{2}$-GOD-HA nanoparticles. (D) Hydrodynamic diameter distribution of $\mathrm{SiO}_{2}, \mathrm{SiO}_{2}-\mathrm{HA}$ and $\mathrm{SiO}_{2}$-GOD-HA nanoparticles measured by DLS.

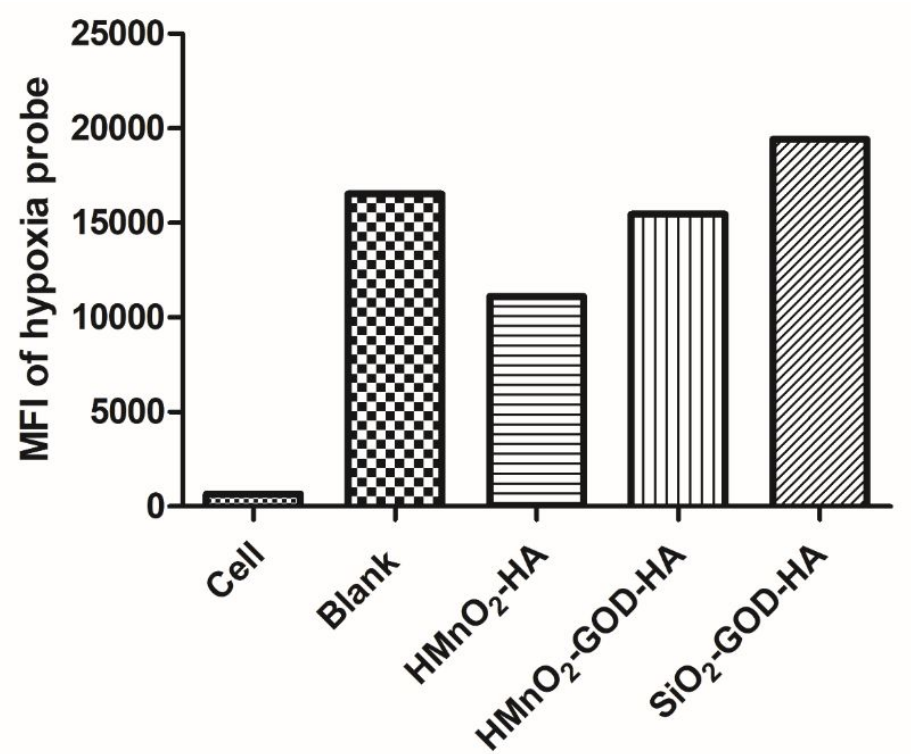

Figure S18. Flow cytometry analysis of the mean fluorescence intensity (MFI) of MDA-MB-231 cells incubated with $\mathrm{HMnO}_{2}-\mathrm{HA}, \mathrm{HMnO}_{2}-\mathrm{GOD}-\mathrm{HA}$ and $\mathrm{SiO}_{2}$-GODHA nanoparticles at an Mn concentration of $20 \mu \mathrm{g} / \mathrm{mL}$ for $8 \mathrm{~h}$ at a hypoxia environment, and further stained with a ROS-ID hypoxia probe. 


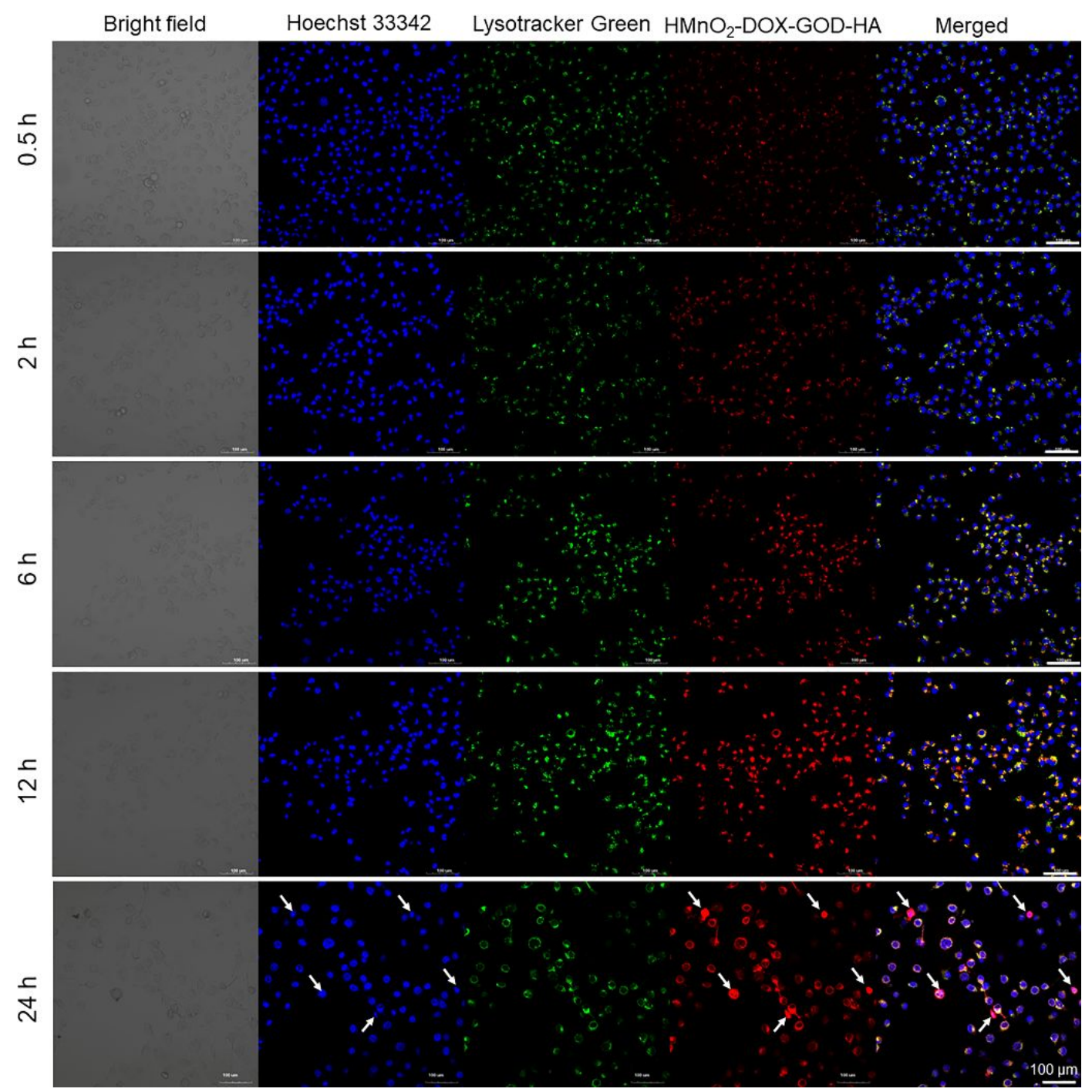

Figure S19. CLSM images of MDA-MB-231 cells treated with $\mathrm{HMnO}_{2}$-DOX-GODHA for various co-incubation time. Cell nucleus were labeled with Hoechst33342 and lysosomes were labeled with Lysotracker Green. Arrows point to the accumulation of released DOX from nanoparticles in nuclei of MDA-MB-231 cells. scale bar $=100 \mu \mathrm{m}$. 


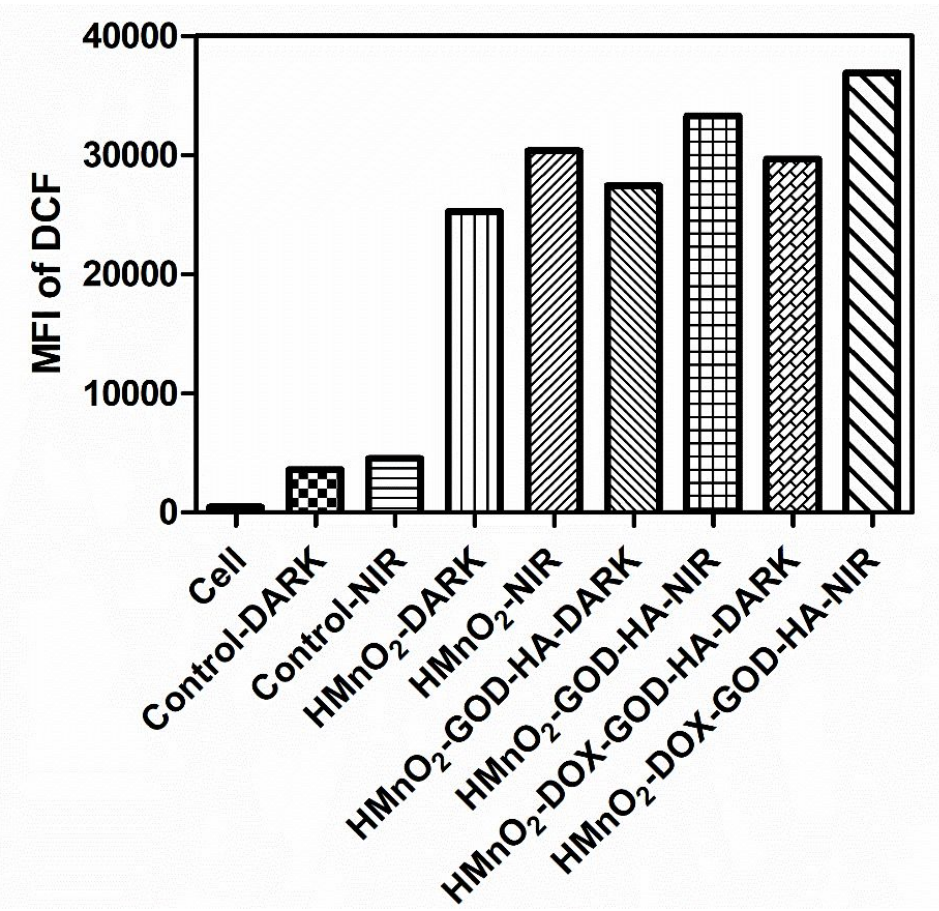

Figure S20. Quantitative analysis of MFI of in MDA-MB-231 cells with various treatments by flow cytometry.
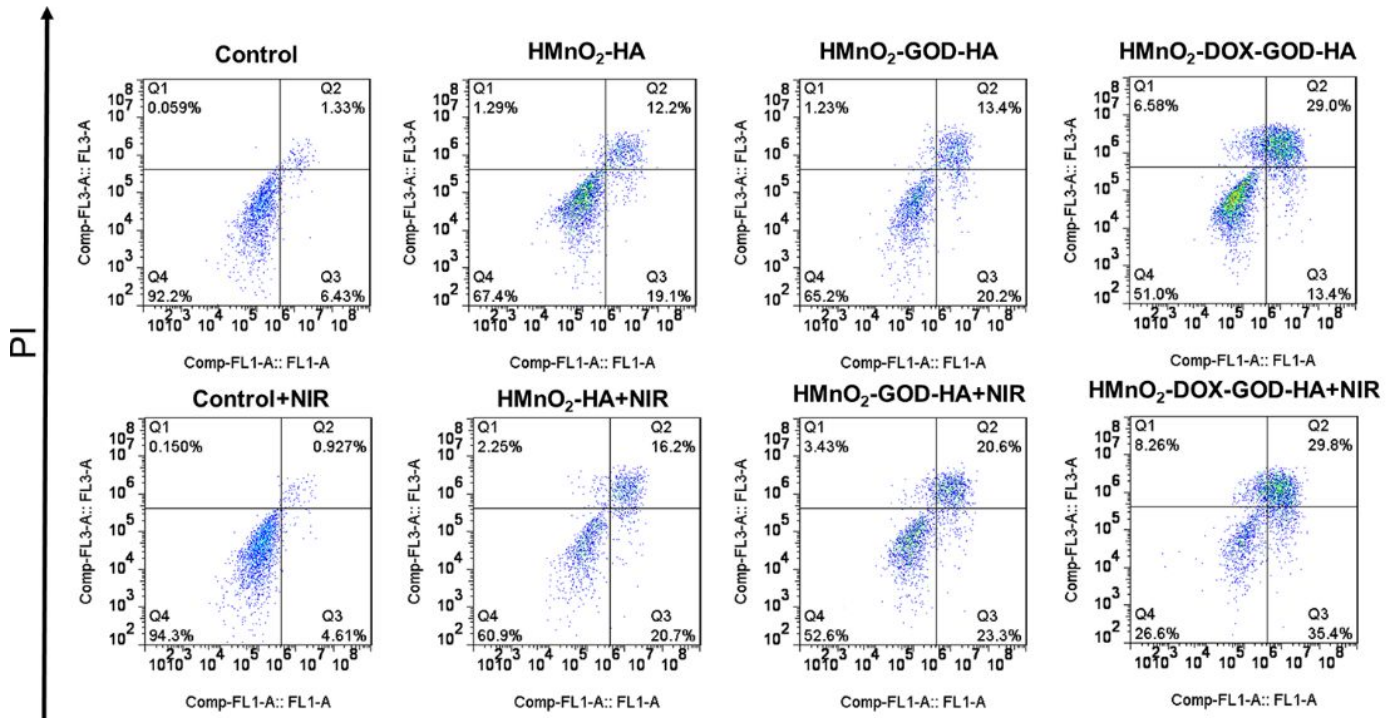

Annexin V-FITC

Figure S21. Apoptosis analysis of MDA-MB-231 cells treated with $\mathrm{HMnO}_{2}-\mathrm{HA}$, $\mathrm{HMnO}_{2}$-HA+NIR, $\mathrm{HMnO}_{2}$-GOD-HA, $\mathrm{HMnO}_{2}$-GOD-HA+NIR, $\mathrm{HMnO}_{2}$-DOX-GOD$\mathrm{HA}$ and $\mathrm{HMnO}_{2}$-DOX-GOD-HA+NIR by Annexin V-FITC/PI staining assay. 


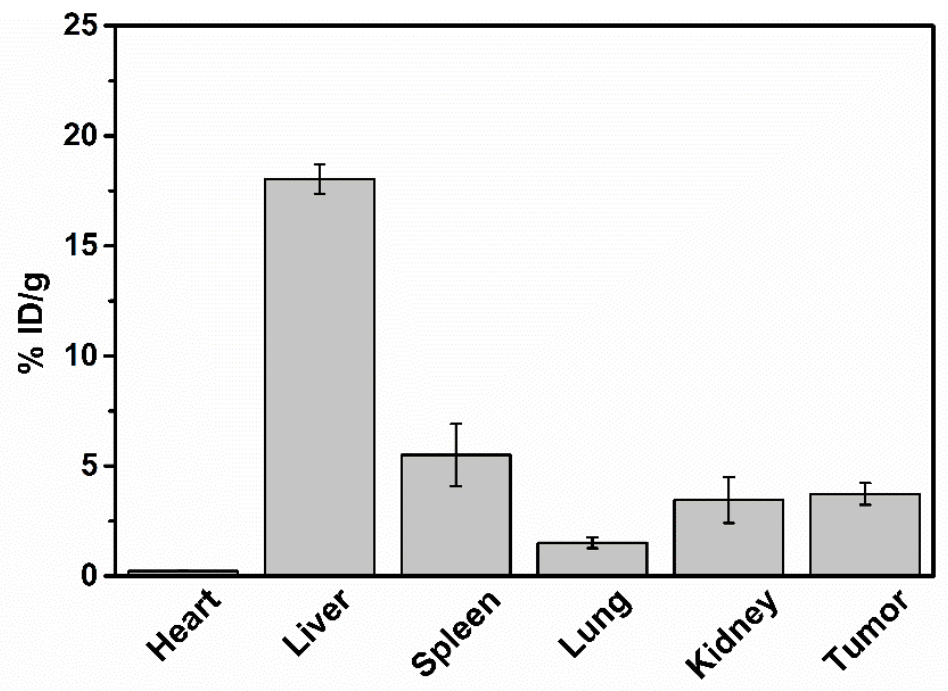

Figure S22. Biodistribution of $\mathrm{HMnO}_{2}$-DOX-GOD-HA after intravenous injection into MDA-MB-231 tumor-bearing mice by measuring Mn concentrations with ICP-MS.

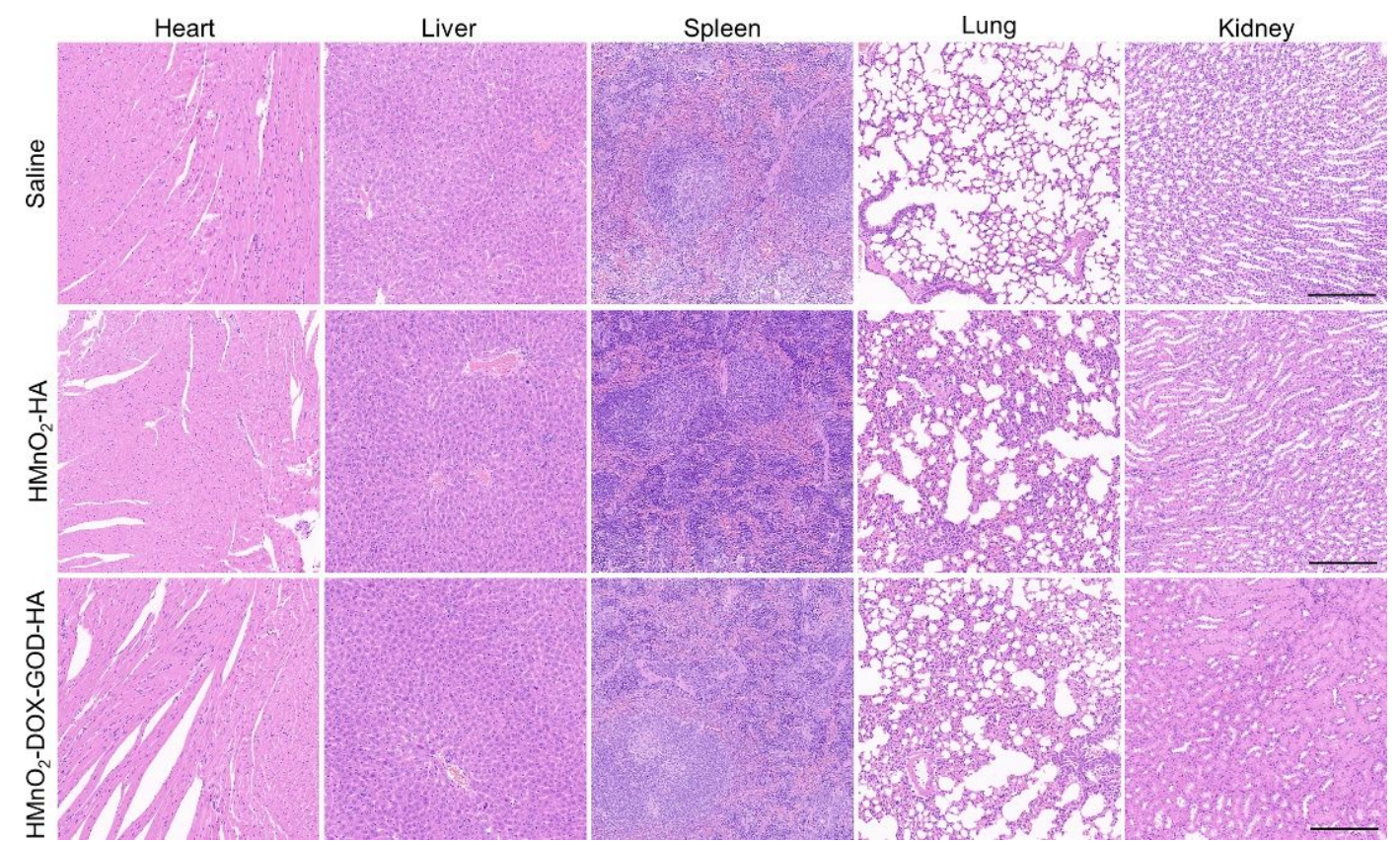

Figure S23. Histological sections in the acute toxicity test. H\&E histology images of heart, liver, spleen, lung, and kidney of the mice after treatment with saline, $\mathrm{HMnO} 2-$ HA or HMnO2-DOX-GOD-HA for $72 \mathrm{~h}$ at a dose of $4 \mathrm{mg}$ Mn per $\mathrm{kg}, 5.6 \mathrm{mg}$ DOX per $\mathrm{kg}$. The scale bar is $200 \mu \mathrm{m}$. 


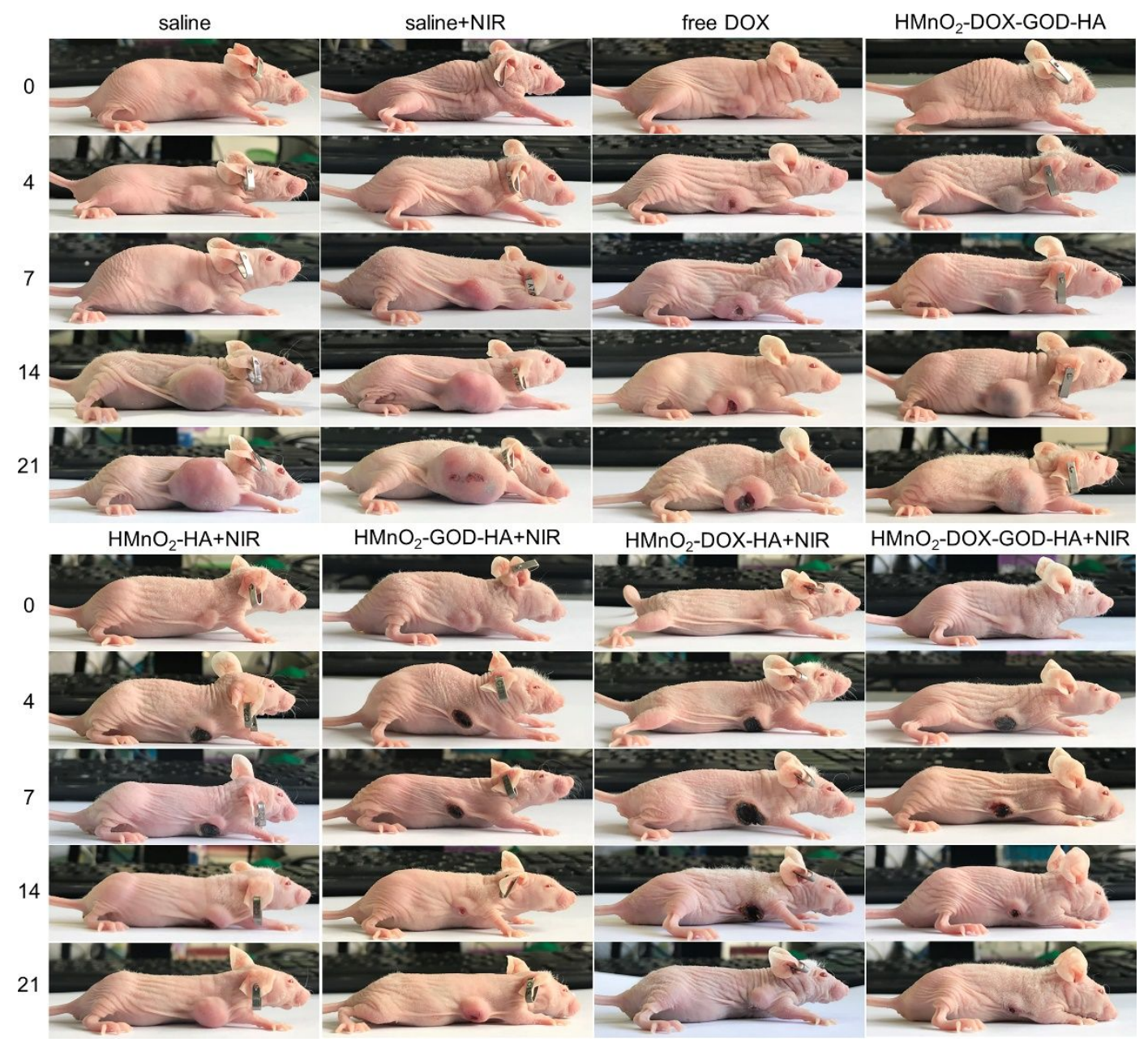

Figure S24. Representative photographs of mice after various treatments. 

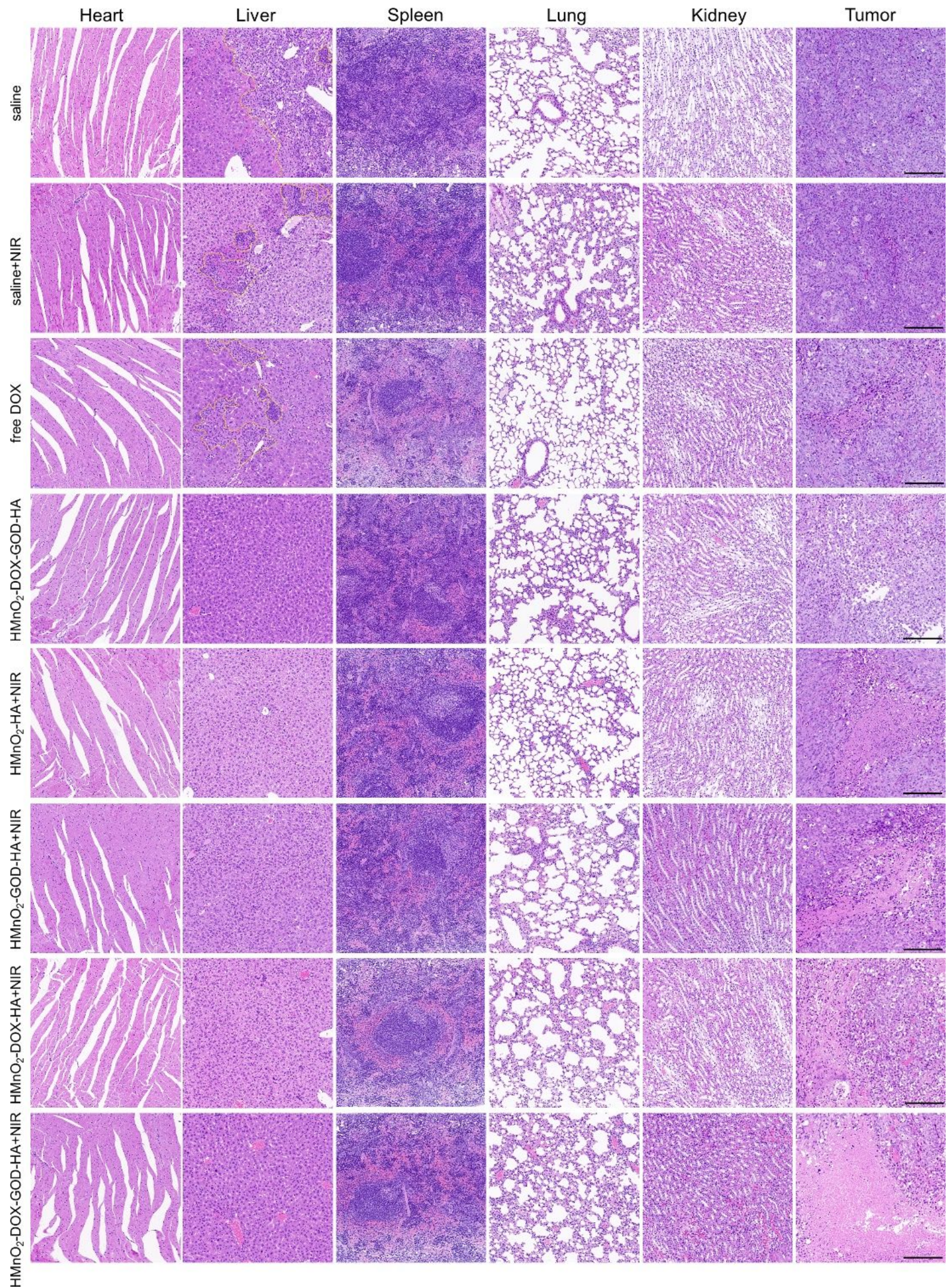

Figure S25. taining of the major organs and tumors from the mice treated with saline, saline + NIR, free DOX, $\mathrm{HMnO}_{2}$-DOX-GOD-HA, $\mathrm{HMnO}_{2}-\mathrm{HA}+\mathrm{NIR}, \mathrm{HMnO}_{2}$-GOD$\mathrm{HA}+\mathrm{NIR}$ and $\mathrm{HMnO}_{2}$-DOX-GOD-HA + NIR for 21 days. The yellow dotted circle represents tumor metastases in the liver. The scale bar is $200 \mu \mathrm{m}$. 


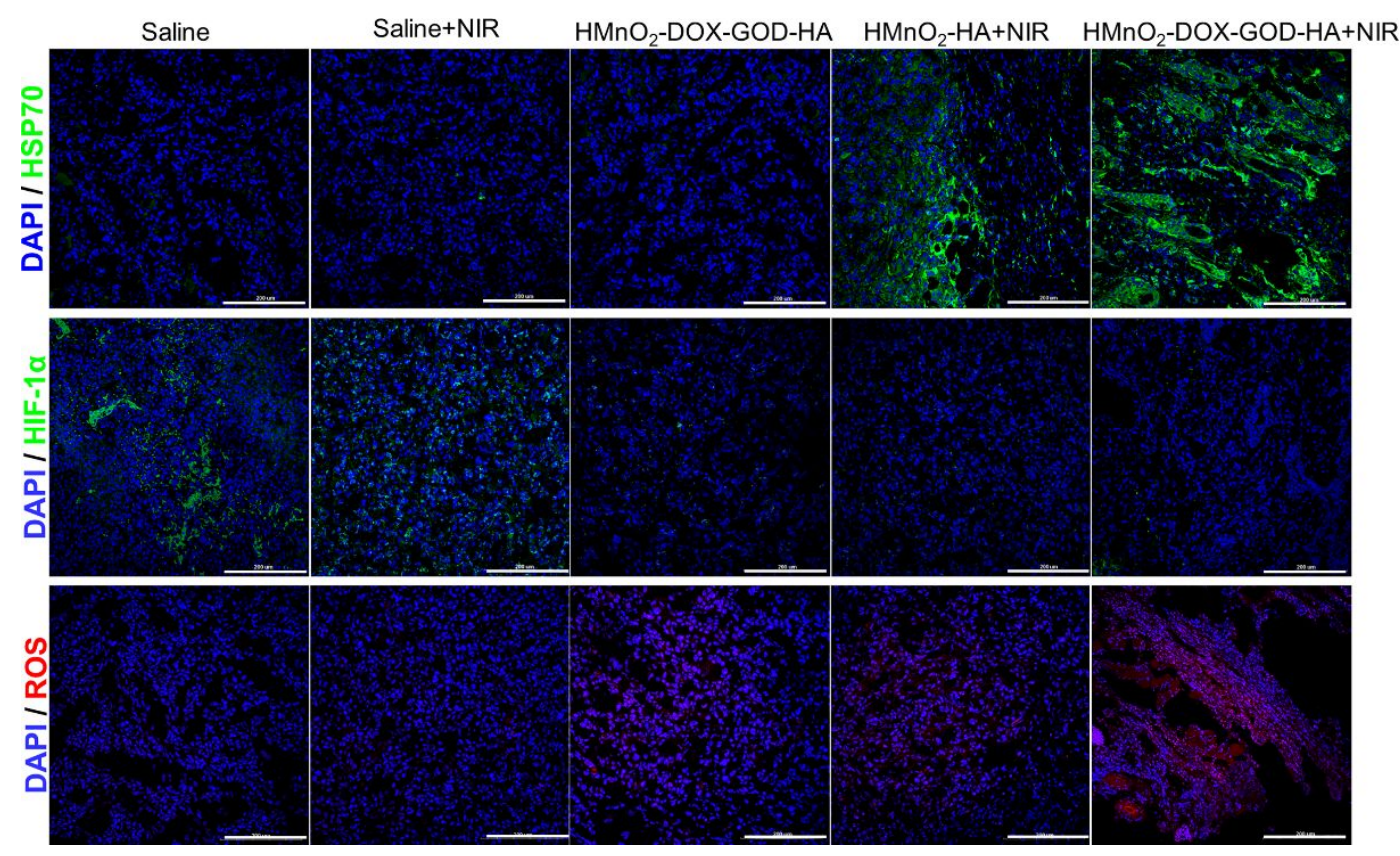

Figure S26. Representative HSP70, HIF-1 $\alpha$ and ROS immunofluorescence images in tumor tissues of each group after different treatments. All the scale bars are $200 \mu \mathrm{m}$. 


\section{References}

1. Liu, Y.; Ai, K.; Liu, J.; Deng, M.; He, Y. Lu, L. Dopamine-melanin colloidal nanospheres: an efficient near-infrared photothermal therapeutic agent for in vivo cancer therapy. Adv. Mater. 2013, 25, 1353-1359.

2. Roper, D. K.; Ahn, W.; Hoepfner, M. Microscale heat transfer transduced by surface plasmon resonant gold nanoparticles. J. Phys. Chem. C 2007, 111, 36363641.

3. Jiang, R.; Huang, T.; Liu, J.; Zhuang, J.; Yu, A. A novel method to prepare nanostructured manganese dioxide and its electrochemical properties as a supercapacitor electrode. Electrochim. Acta 2009, 54, 3047-3052.

4. Vasi, A. M.; Popa, M. I.; Butnaru, M.; Dodi, G.; Verestiuc, L. Chemical Functionalization of Hyaluronic Acid for Drug Delivery Applications. Mater. Sci. Eng., C 2014, 38, 177-185.

5. Xiong, S. Q.; Wang, Y.; Yu, J. R.; Chen, L.; Zhu, J.; Hu, Z. M. Polydopamine particles for next-generation multifunctional biocomposites. J. Mater. Chem. A $2014,2,7578-7587$.

6. Iannace, S.; Ambrosio, L.; Nicolais, L.; Rastrelli, A.; Pastorello, A. Thermochemical properties of hyaluronic acid-derived products. J. Mater. Sci.: Mater. Med. 1992, 3, 59-64.

7. Tully, J.; Fakhrullin, R.; Lvov, Y. In Nanomaterials and Nanoarchitectures: A Complex Review of Current Hot Topics and their Applications; Bardosova, M., Wagner, T., Eds.; Springer Netherlands: Dordrecht, 2015; Chapter 1, pp 87-118 